ARTICLE

DOI: $10.1038 / s 41467-018-05784-3$

\title{
Single-cell analysis reveals that stochasticity and paracrine signaling control interferon-alpha production by plasmacytoid dendritic cells
}

Florian Wimmers (10) 1,2, Nikita Subedi ${ }^{3,4}$, Nicole van Buuringen, Daan Heister ${ }^{1}$, Judith Vivié ${ }^{5}$, Inge Beeren-Reinieren ${ }^{1}$, Rob Woestenenk ${ }^{6}$, Harry Dolstra ${ }^{6}$, Aigars Piruska7, Joannes F.M. Jacobs ${ }^{8}$, Alexander van Oudenaarden ${ }^{5}$, Carl G. Figdor ${ }^{1}$, Wilhelm T.S. Huck ${ }^{7}$, I. Jolanda M. de Vries ${ }^{1}$ \& Jurjen Tel(B) 1,3,4

Type I interferon (IFN) is a key driver of immunity to infections and cancer. Plasmacytoid dendritic cells ( $\mathrm{pDCs}$ ) are uniquely equipped to produce large quantities of type I IFN but the mechanisms that control this process are poorly understood. Here we report on a dropletbased microfluidic platform to investigate type I IFN production in human pDCs at the singlecell level. We show that type I IFN but not TNF $\alpha$ production is limited to a small subpopulation of individually stimulated pDCs and controlled by stochastic gene regulation. Combining single-cell cytokine analysis with single-cell RNA-seq profiling reveals no evidence for a pre-existing subset of type I IFN-producing pDCs. By modulating the droplet microenvironment, we demonstrate that vigorous $\mathrm{pDC}$ population responses are driven by a type I IFN amplification loop. Our study highlights the significance of stochastic gene regulation and suggests strategies to dissect the characteristics of immune responses at the single-cell level.

\footnotetext{
${ }^{1}$ Department of Tumor Immunology, Institute for Molecular Life Sciences, Radboud University Medical Center, Nijmegen 6525 GA, The Netherlands.

2 Institute for Immunity, Transplantation and Infection, Stanford University, Stanford 94305 CA, USA. ${ }^{3}$ Department of Biomedical Engineering, Laboratory of Immunoengineering, Eindhoven University of Technology, Eindhoven 5612 AZ, The Netherlands. ${ }^{4}$ Institute for Complex Molecular Systems, Eindhoven University of Technology, Eindhoven 5612 AZ, The Netherlands. ${ }^{5}$ Hubrecht Institute - KNAW and University Medical Center Utrecht, Utrecht 3584 CT, The Netherlands. ${ }^{6}$ Department of Laboratory Medicine, Laboratory of Hematology, Radboud University Medical Center, Nijmegen 6525 GA, The Netherlands. ${ }^{7}$ Department of Physical Organic Chemistry, Institute for Molecules and Materials, Radboud University, Nijmegen 6525 HP, The Netherlands. ${ }^{8}$ Department of Laboratory Medicine, Laboratory Medical Immunology, Radboud University Medical Center, Nijmegen 6525 GA, The Netherlands. These authors contributed equally: Carl G. Figdor, Wilhelm T.S. Huck, I. Jolanda M. de Vries. Correspondence and requests for materials should be addressed to J.T. (email: J.Tel@tue.nl)
} 
$\mathrm{P}$ lasmacytoid dendritic cells (pDCs) are blood circulating innate immune cells with the unique ability to rapidly release large quantities of type I interferon (IFN) for antiviral immunity ${ }^{1-3}$. pDC-produced type I IFN is associated with effective anti-cancer immunity but is also a driver of autoimmune diseases $^{4-8}$. Type I IFN production by pDCs is initiated when nucleic acids trigger the endosomal Toll-like receptors (TLRs) 7 or 9 leading to the activation of transcription factor interferon regulatory factor-7 (IRF7), which only pDCs express constitutively and at high levels ${ }^{9-11}$. Several $\mathrm{pDC}$ subclasses were proposed and single-cell genomic profiling revealed ample variation in the molecular outfit of individual DCs ${ }^{12-16}$. These individual differences may have an impact on the ability of each pDC to produce type I IFN, and in non-pDC model systems random differences between virus-infected cell populations, attributed to stochastic gene regulation, caused significant variation in the production of type I IFN ${ }^{17-21}$. Additionally, type I IFN production by $\mathrm{pDCs}$ can be modulated by the microenvironment via soluble factors or cell surface receptors ${ }^{22-27}$. It is currently not known how pDC populations combine the complex information from TLR signaling and microenvironmental factors with random variations in the molecular outfit of individual pDCs to generate robust type I IFN responses. The question remains whether pDCs display stochastic expression of type I IFN despite high IRF7 expression, and whether pDC populations exploit environmental cues to counterbalance potential heterogeneity arising from this phenomenon.

Here, we developed a droplet-based microfluidic platform to dissect the human pDC-driven type I IFN response at the singlecell level within a tunable microenvironment. Generating thousands of identical droplets at high throughput allows massively parallelized single-cell experiments within these bioreactors. Recent technological breakthroughs in the field of droplet-based microfluidics increased the throughput of single-cell DNA and RNA-sequencing experiments by orders of magnitude ${ }^{28,29}$. Previous attempts by our lab and others to leverage this power for the analysis of cytokine secretion were hampered in their translation into practice due to complex detection equipment or difficult handling conditions $s^{30,31}$. Here, we demonstrate the detection of cytokine secretion and activation marker expression by individually stimulated cells in droplets and reveal stochastic differences in pDC-driven type I IFN production. Single-cell RNA-sequencing (ScRNA-seq) of these cells allowed us to profile the transcriptional changes in each cell upon perturbation with TLR ligands and links transcriptional variation to cytokine secretion at the protein level. Finally, by varying key droplet parameters, we find that single pDCs collaborate to amplify their activity and generate population-driven type I IFN responses.

\section{Results}

Functional pDC heterogeneity arises early after stimulation. pDCs operate in complex microenvironments that influence their cellular state. To investigate the intrinsic potential of single pDCs to produce IFNa without interference of other cells, we developed a droplet microfluidic single-cell assay for the detection of cytokine secretion (Fig. 1a). In short, pDCs were coated with capture reagents for cytokine readout and encapsulated in picoliter droplet microenvironments using a microfluidic device (Fig. 1b, c). During in-droplet incubation, produced IFNa and tumor necrosis factor- $\alpha(\mathrm{TNF} \alpha)$ was captured on the cell surface by the cytokine capture reagents. After breaking the emulsion, pDCs were isolated and analyzed via multicolor flow cytometry. Each droplet served as a standardized and independent cell reactor and allowed the investigation of tens of thousands of individually stimulated cells simultaneously. This massively parallel approach facilitated the characterization of rare, truly single-cell behavior. This system greatly exceeds the throughput and possibilities when compared to conventional limited dilution experiments which require numerous replicate cultures and, crucially, cannot prohibit cellular crosstalk. Further, the low droplet volume greatly reduced reagent consumption and allowed us to work with small numbers of (primary) cells. We routinely probed rare pDCs using as few as 40,000 cells as input, showing that our technique is highly suited for the use of small biological samples. Importantly, our dropletbased cytokine capture approach enables sensitive cytokine detection and makes no use of transport inhibitors, which negatively impact cellular function and viability. This enabled us to measure cytokine secretion for extended time periods in an accumulative rather than snapshot fashion and facilitated the analysis of extremely early secretion events within the first $30 \mathrm{~min}$ of stimulation. Early activation events are problematic to investigate with transport inhibitor-based methods as they negatively impact cell signaling, thereby distorting the measurement. In contrast to microtiter-based approaches, our microfluidic setup makes use of computer-controlled syringe pumps. This allowed us to precisely control environmental factors and vary droplet volume and local cell density in a range that currently cannot be obtained with conventional cultures.

First, we encapsulated pDCs in picoliter droplets (average $92 \mathrm{pL}$, SEM $1.8 \mathrm{pL}, n=85)$ with an encapsulation efficiency of approximately $6 \%$ cell-containing drops (Fig. 1d) of which $96 \%$ contained a single cell (Fig. 1e). Cells were incubated with the synthetic nucleic acid compound CpG-C (TLR9 agonist) and analyzed by flow cytometry (Fig. 1f). Strikingly, only a minor subset of pDCs produced IFNa, which emerged as early as $2 \mathrm{~h}$ after stimulation and peaked after $6 \mathrm{~h}$ of stimulation (Fig. 1g, h). In contrast, we observed that virtually all $\mathrm{pDCs}$ produced TNFa during incubation in droplets (Fig. 1g, h). Similarly, the majority of pDCs was positive for the activation markers CCR7, CD40, and CD86 and most pDCs were highly multifunctional (Fig. 1i-k). Furthermore, we confirmed previous findings that a recently discovered subset of pDC-like progenitor cells, called AS DCs, was not involved in IFNa production (Supplementary Fig. 1) ${ }^{15}$.

Next, we studied the capacity of TLR signaling to modulate the probability of pDCs to produce IFNa. We encapsulated cells with varying concentrations of CpG-C and measured the fraction of cells producing IFNa (Fig. 2a). Surprisingly, we only observed minor variations in the fraction of $\mathrm{pDC}$ secreting IFNa irrespective of the concentration of CpG-C. In contrast, the production of TNFa, the expression of the activation markers CCR7, CD40, and CD86, and cell viability all positively correlated with $\mathrm{CpG}-\mathrm{C}$ concentration (Fig. 2a, Supplementary Fig. 2). To exclude CpG-C-specific limitation in the TLR9 signaling pathway, we stimulated pDCs with the synthetic TLR7/8-agonist R848 (Fig. 2b) and the strong IFNa inducer TLR9 agonist CpG-A (Supplementary Fig. 3). Similar to CpG-C stimulation, only a small fraction of pDCs produced IFNa and this effect was independent of stimulus concentration. Thus far, virtually all knowledge on IFNa secretion by human pDCs is based on bulk cultures. Therefore, cells from the same donor were analyzed by microfluidics and bulk culture side-by-side. Our results demonstrate that individually stimulated cells in droplets indeed have an inferior capacity to secrete IFNa as compared to bulk stimulated cells (Supplementary Fig. 4). Finally, to rule out that the observed IFNa production was due to stimulus-independent constitutive secretion, we stimulated pDCs with either interleukin-3 (IL-3) or CpG-C. The pDCs treated with IL-3, a survival factor for pDCs, which only survive briefly ex vivo when left unstimulated, showed a significantly reduced probability to produce IFNa (Fig. 2c). To exclude that IFNa production by single pDCs is delayed compared to bulk analysis, we incubated pDCs for $12 \mathrm{~h}$ and $24 \mathrm{~h}$ but only observed small deviations (Fig. 2d). 
Together, our data demonstrate that our microfluidic assay is suited for the sensitive detection of cytokine secretion and protein expression by single cells. Functional heterogeneity emerges immediately after TLR activation in pDCs, as only a small fraction of cells is able to produce IFNa. IFNa production is enhanced by TLR signaling but appears to be regulated by an additional stochastic, i.e. random, component which is not associated with strength, amplitude, or duration of cell activation.
Type I IFN is an important regulator of early pDC function. Cellular heterogeneity often emerges from random processes during gene transcription ${ }^{32}$. To probe whether the observed differences in IFNa production originate from such stochastic gene regulation or whether a privileged $\mathrm{pDC}$ subset already exists at steady state, we employed scRNA-seq to profile the onset of the type I IFN response upon perturbation with CpG-C. Freshly isolated pDCs from a healthy donor were encapsulated in droplets and individually stimulated with $\mathrm{CpG}-\mathrm{C}$ using our

a

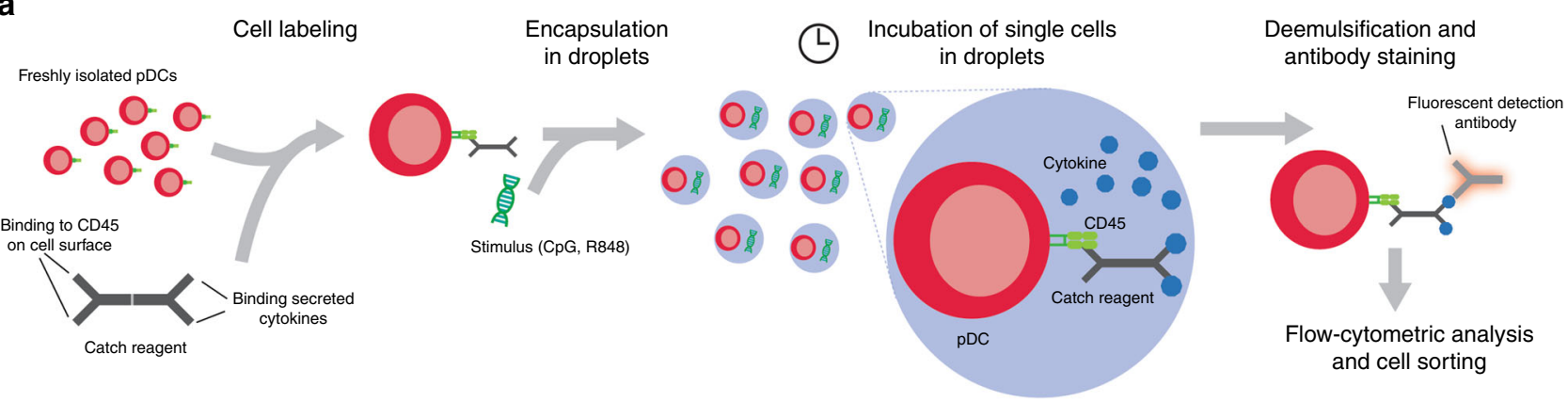

b
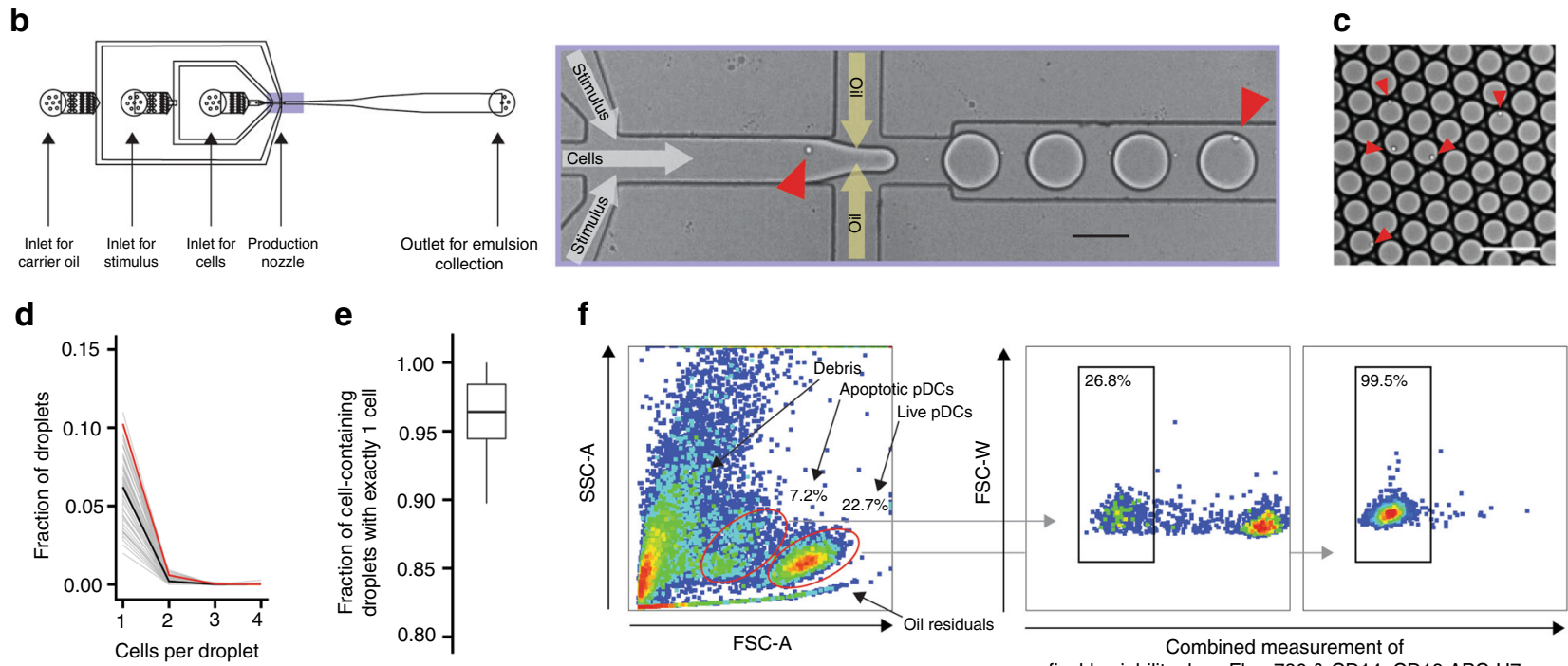

f

g
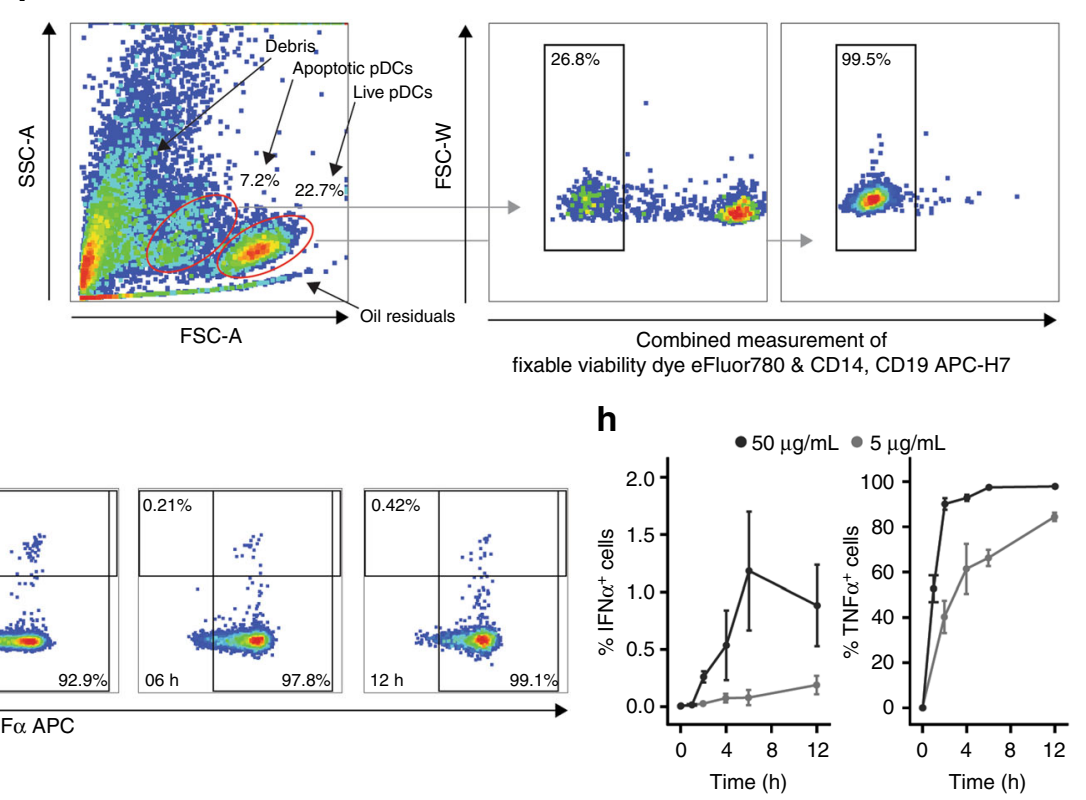

i

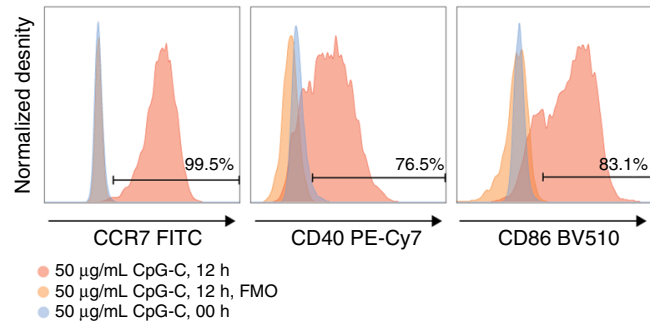

j

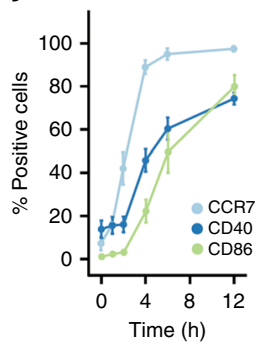

$\mathbf{k}$

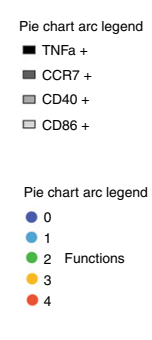

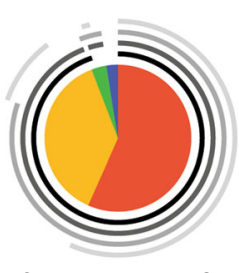

Gated on IFN $\alpha^{+}$pDCs

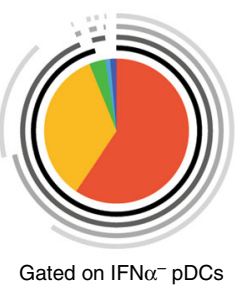


microfluidic platform (Fig. 3a). After incubation for 0 , 1 , or $2 \mathrm{~h}$, the emulsion was broken, cells were stained for cytokine secretion, and 384 cells at each time point were sorted into well plates for scRNA-seq (Fig. 3b). Single cells were processed using the SORT-Seq (sorting and robot-assisted transcriptome sequencing) protocol followed by sequencing of $\sim 0.1$ million to 0.2 million paired-end reads per cell ${ }^{33}$. At $2 \mathrm{~h}$, when we detected the first $\mathrm{IFNa}^{+}$pDCs, we enriched for this subset by sorting $39 \mathrm{IFNa}^{+}$ pDCs before randomly filling up remaining wells with $\mathrm{IFNa}^{+}$and $\mathrm{IFNa}^{-}$cells. In total, we profiled 1152 cells with an average of 4677 transcripts per cell and 1574 unique genes detected per cell. After filtering, down-sampling, and removal of 141 DCs that clustered separately in initial analyses and expressed gene signatures of non-pDC subsets $\left(\mathrm{CD} 1 \mathrm{c}^{+}, \mathrm{CD} 141^{+}\right)$, the final dataset contained 774 cells expressing 13,214 genes (Supplementary Fig. 5) ${ }^{15}$.

Unsupervised $k$-medoid clustering of the correlation matrix combined with outlier detection using the raceID2 algorithm suggested the presence of 8 cell clusters (Supplementary Figure 6A-E) which were visualized in two dimensions using tdistributed stochastic neighbor embedding (t-SNE) (Fig. 3c, d; Supplementary Fig. $6 \mathrm{~F}-\mathrm{H})^{34}$. We observed two clusters of unstimulated cells, $\mathrm{Cl} 1$ and $\mathrm{Cl}$. $\mathrm{Cl} 1$ also contained a group of cells that expressed characteristics of the described CD2 ${ }^{\text {hi }}$ pDC and AS DC subsets (Supplementary Fig. 7) ${ }^{12,15}$. Cells stimulated for $1 \mathrm{~h}$ mapped into $\mathrm{Cl} 2$ with few cells also present in $\mathrm{Cl} 3$ and $\mathrm{Cl} 8 \mathrm{Cl} 4, \mathrm{Cl} 6$, and $\mathrm{Cl} 5$ were dominated by pDCs that were stimulated for $2 \mathrm{~h}$. Cells sorted as $\mathrm{IFNa}^{+}$mapped to $\mathrm{Cl} 4$ and $\mathrm{Cl} 5$ at equal fractions and more than $60 \%$ of cells in $\mathrm{Cl} 5$ were sorted as $\mathrm{IFNa}^{+}$(Fig. 3e). The pDCs mapping to $\mathrm{Cl} 5$ produced high levels of IFNa as measured by flow cytometry (Fig. 3f) and cells sorted as IFNa ${ }^{+}$expressed high levels of type I IFN genes, such as IFNA2, and IFNB1, as well as the interferon-inducible gene IFIT2 (Fig. 3g). Differential gene expression analysis showed an enrichment of type I IFN genes or type I IFN-induced genes in $\mathrm{Cl} 5$ as compared to all other cells (Fig. 3h). In contrast, no obvious transcriptionally distinct $\mathrm{pDC}$ subset that could predict type I IFN production was observed at steady state. This could either be because type I IFN production is genuinely a stochastic process, or because the nature of such a privileged cell state cannot be determined a priori by present technology. Similar results were obtained when pDCs from two additional healthy donors were profiled at steady state (Supplementary Fig. 8).

Next, we compared the gene expression of individually stimulated pDCs and unstimulated cells. We argued that the underlying mechanisms of $\mathrm{Cl} 5 \mathrm{pDCs}$ ' unique activation state might become evident when comparing the differential gene expression profiles of all stimulated pDC clusters. On average, $\mathrm{Cl} 5$
pDCs showed 77 upregulated genes ( $\log 2$ (fold change) $>1.5$; $p$ value $<10^{-8}$ ) and 1 downregulated gene $(\log 2$ (fold change) $<$ $-1.5 ; p$ value $<10^{-8}$ ) compared to unstimulated pDCs in Cl1 (Fig. 4a). Type I IFN and IFN response genes were among the most upregulated genes as well as several genes that support IFNa production in pDCs including MIR155HG, HSPA1A, and HSP90AA1 (Fig. 4b) ${ }^{35-37}$. Notably, the chemokines CCL3 and CCL4 that bind to the chemokine receptor CCR5 were upregulated. CCR5 is expressed on all pDCs and CCL3/4CCR5 signaling might be responsible for the generation of large pDC clusters early after activation ${ }^{38,39}$. Next, we checked for other clusters with similar expression patterns. $\mathrm{Cl} 5$ cells shared many upregulated genes with cells from other clusters, especially $\mathrm{Cl} 3$ and $\mathrm{Cl} 4$; however, they also retained a group of uniquely upregulated genes centered around type I IFN production (Fig. 4c). Gene enrichment and functional annotation analysis using DAVID (Database for Annotation, Visualization and Integrated Discovery) showed that upregulated genes in $\mathrm{Cl} 5$ pDCs were enriched for anti-viral responses, cytokine responses, and apoptosis (Fig. 4d and Supplementary data 1-4) 40,41 . Similarly, type I IFN-related or -induced pathways were uniquely enriched in Cl5 genes, including TLR signaling, cytosolic DNA sensing, and the RIG-I-like pathway.

These results demonstrate that our microfluidic platform is ideally suited to work in conjunction with scRNA-seq to link functional information from extremely rare cells $(<0.02 \%$ IFNaproducing pDCs) to whole transcriptome profiling. Together, the data show that type I IFN-producing cells possess unique transcriptional features, many of which are associated with autocrine type I IFN signaling. ScRNA-seq data revealed no evidence for a privileged pDC subset at steady state but type I IFN appears to be an important orchestrator of early pDC activation. The question remains of how $\mathrm{pDC}$ populations regulate the cellular heterogeneity originating from variation in type I IFN production.

Environmental factors modulate type I IFN production. In vivo, $\mathrm{pDCs}$ act in a dynamic microenvironment and migrate considerably during their life cycle. To assess the impact of environmental changes on the observed heterogeneity during pDC-driven type I IFN responses, we systematically varied key droplet parameters (Fig. 5a).

First, we generated droplets of varying size, covering several orders of magnitude (Fig. 5b). Single pDCs were encapsulated in droplets ranging from 31 to $1209 \mathrm{pL}$ and stimulated for $12 \mathrm{~h}$ (Fig. 5c). No significant difference in the fraction of IFNasecreting cells was detected (Fig. 5d, colored dots). Comparison with pDCs from additional donors, which were encapsulated in droplets of up to $3371 \mathrm{pL}-\mathrm{a}$ volume comparable to the average

Fig. 1 Single-cell analysis reveals functional heterogeneity within individually stimulated pDCs. a Schematic overview of the droplet microfluidic assay. The pDCs were coated with cytokine capture reagents, encapsulated in picoliter droplets, and stimulated with TLR ligands. After incubation, cells were stained for viability, cytokine, and surface marker expression, and analyzed by flow cytometry. b Schematic overview of the employed microfluidic chip with microscopic image of the flow-focusing nozzle for the encapsulation of cells in droplets. $\mathbf{c}$ Microscopic image of emulsion after droplet production. $\mathbf{b}$, $\mathbf{c}$ Red arrows indicate cells. Scale bars equal $100 \mu \mathrm{m}$. d The pDCs were encapsulated at a concentration of 1,300,000 cells/mL in $92 \mathrm{pL}$ droplets. The distribution of cells in droplets was measured by manual analysis of microscopic images showing the emulsion directly after production. Shown is the fraction of droplets plotted against the number of cells per droplet; $n=85$, black line indicates median, red line indicates predicted values. e Shown is the fraction of cell-containing droplets with exactly one cell; $n=85$. Lines indicate mean, hinges mark interquartile ranges, and whiskers reach to the highest/lowest value that is within $1.5 \times$ interquartile range. f-k The pDCs were treated as described above and stimulated with $5 \mu \mathrm{g} / \mathrm{mL}$ or $50 \mu \mathrm{m} / \mathrm{mL} \mathrm{CpG}-\mathrm{C}$. $\mathbf{f} \mathrm{Viable} \mathrm{pDC}$ were detected by forward scatter (FSC) and side scatter (SSC) analysis and subsequent gating on CD14- CD19- and viability dye ${ }^{-}$cells. $^{-}$IFN $\alpha^{-}$and TNF $\alpha^{-}$ secreting cells were detected within that population. $\mathbf{h}$ Shown is the fraction of cytokine-secreting cells plotted against incubation time; $n(5 \mu g / m L)=3$, $n(50 \mu \mathrm{g} / \mathrm{mL})=6$. i Surface marker-expressing pDCs were identified comparing the expression levels to fluorescence-minus-one controls. $\mathbf{j}$ Shown is the fraction of surface marker-expressing cells plotted against the incubation time; $n>=4$. $\mathbf{k}$ The co-expression of CCR7, CD40, CD86, and TNF $\alpha$ by single IFN $\alpha^{+}$and IFN $\alpha^{-}$pDCs was analyzed. Shown is the relative contribution of each functional response pattern to the total pDC population. $\mathbf{h}, \mathbf{j}$ Dots indicate mean, error bars indicate SEM 

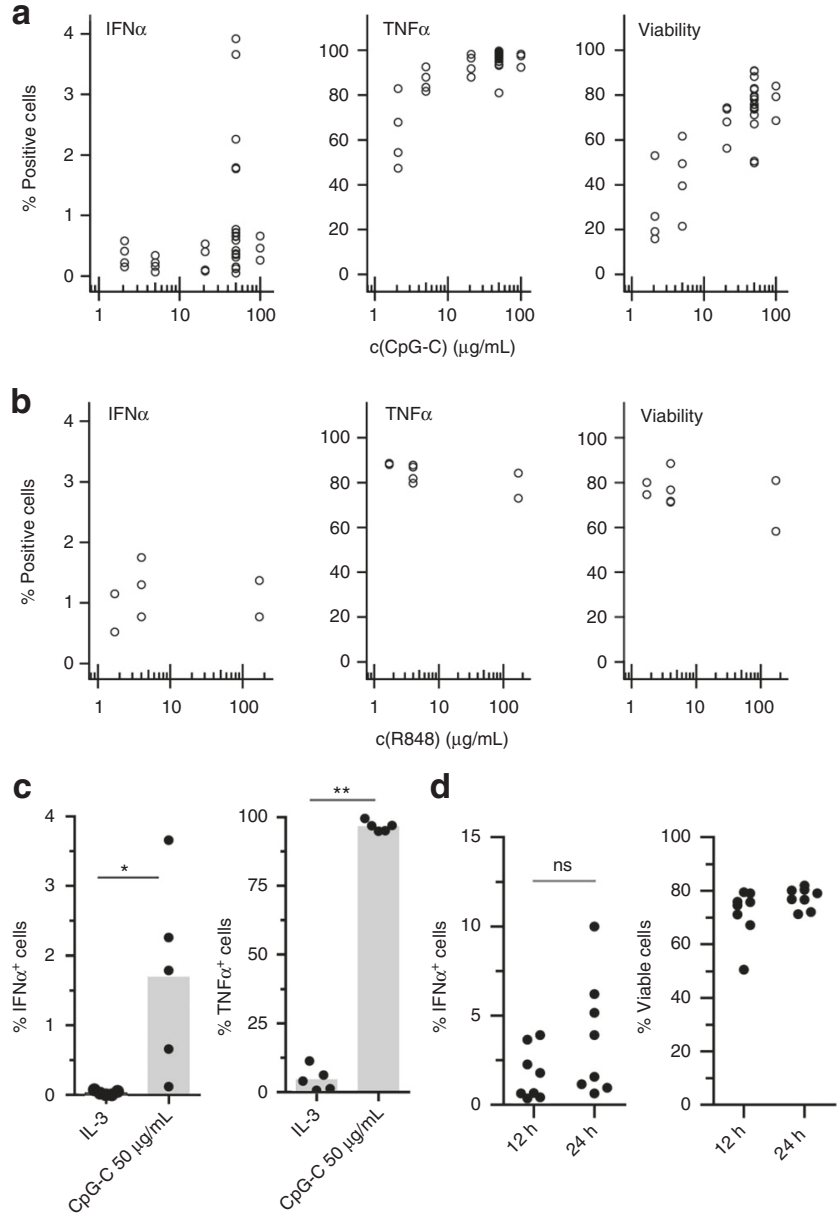

Fig. 2 TLR-L concentration does not influence the fraction of IFN $\alpha$ producing pDCs in droplets. $\mathbf{a}, \mathbf{b}$ The pDCs were coated with capture reagent, encapsulated in picoliter droplets, and stimulated individually with a CpG-C or b R848 for $12 \mathrm{~h}$. After staining for viability, surface marker expression and cytokine secretion, cytokine-secreting cells, and viable cells were detected via flow cytometry. Shown is the fraction of markerexpressing cells plotted against TLR ligand concentration. Different concentrations were tested in different donors; $\mathbf{a} n \geq 3, \mathbf{b} n \geq 2$. c The pDCs were treated as described above and stimulated with $0.01 \mu \mathrm{g} / \mathrm{mL} \mathrm{IL}-3$ or $50 \mu \mathrm{g} / \mathrm{mL} \mathrm{CpG-C}$. Shown is the fraction of cytokine-secreting cells plotted against treatment condition; $n=5$. Bars indicate mean. $\mathbf{d}$ The $p D C s$ were treated as described above and stimulated with $50 \mu \mathrm{g} / \mathrm{mL} \mathrm{CpG-C}$ for $12 \mathrm{~h}$ or $24 \mathrm{~h}$. Shown is the fraction of IFN $\alpha$-secreting or viable cells plotted against treatment condition; $n=8(\mathbf{c}, \mathbf{d})$ Mann-Whitney test ${ }^{\star} p<0.05$, ${ }^{\star \star} p$ $<0.01$

volume of a single $\mathrm{pDC}$ in a perfectly mixed microtiter plateshowed no increase in the fraction of IFNa-secreting cells (Fig. 5d, gray dots).

Previous studies indicated that pDCs build homologous cell clusters upon stimulation, indicating that cellular crosstalk might be involved in their activation process ${ }^{2,39}$. To test this, we stimulated pDCs at various cell densities in microtiter plates in bulk (Supplementary Fig. 9A). Indeed, the fraction of IFNa-expressing pDCs depended on cell density (Supplementary Fig. 9B-F).

Communication between abovementioned pDCs in bulk can, thus, amplify the fraction of IFNa-producing cells. To get more insight into the nature of this communication, we tested whether crosstalk between two random interacting cells would be sufficient to enable IFNa production. We encapsulated $\mathrm{pDCs}$ in
$90 \mathrm{pL}$ droplets and gradually increased the fraction of droplets containing multiple cells (Fig. 5e). The fraction of IFNa-secreting cells increased slightly with the fraction of multiple cells per drop but did not match the predictions of a random interaction model (Fig. 5f, red). In contrast, the increase was better described by an alternative model based on the assumption that the early IFNaproducing pDCs activate co-encapsulated cells to produce IFNa as well (blue). However, in the employed system, we cannot rule out the possibility that the increase was caused by passive diffusion of cytokines or capture reagent between two coencapsulated cells (Supplementary Fig. 10).

Together, these results show that the microenvironment-in this case represented by surrounding $\mathrm{pDCs}$ - has a critical impact on the probability of a $\mathrm{pDC}$ to produce IFNa.

Priming with type I IFN increases the chance to produce IFNa. Communication between IFNa-producing pDCs and surrounding pDCs occurs either in a juxtacrine or paracrine fashion. To elucidate whether paracrine signaling is the driving factor, freshly isolated pDCs were primed for $2 \mathrm{~h}$ with conditioned medium (CM) harvested from overnight bulk pDC cultures (Fig. 6a). After priming, pDCs were thoroughly washed, coated with capture reagent, encapsulated in picoliter droplets, and stimulated individually with CpG-C. Priming cells with $10 \% \mathrm{CM}$ significantly increased the fraction of single $\mathrm{pDCs}$ that produced IFNa (Fig. 6b). In contrast, no effect was observed when cells were primed with remnant CpG-C, fresh cell culture medium, or primed without subsequent TLR stimulation. Similar to previous experiments, IFNa-secreting cells were highly multifunctional (Fig. 6c). Interestingly, the fraction of IFNa-secreting pDCs depended on the concentration of the CM, but not on the concentration of CpG-C (Fig. 6d, e). These findings indicate that priming modulates the probability of a $\mathrm{pDC}$ to produce IFNa but does not directly induce IFNa production.

To identify the responsible factor for the priming effect, we tested several cytokines described to positively affect IFNa-production by $\mathrm{pDCs}^{22,27}$. An initial screen revealed that only IFN $\beta$-which acts similar to IFNa via the IFN $\alpha / \beta$-receptor-increased the average per-cell IFNa production by pDCs cultured in microtiter plates at low cell density (Supplementary Fig. 11A, B). Furthermore, blocking the IFN $\alpha / \beta$ receptor and adding neutralizing antibodies against IFNa and $-\beta$ inhibited the positive effect of CM on per-cell IFNa production. Priming of pDCs with IFN $\beta$ also led to an increase in the fraction of low-density cultured pDCs producing IFNa as measured by flow cytometry (Supplementary Fig. 11C). Finally, priming with IFN $\beta$ increased the fraction of IFNa-secreting cells in droplets to a similar extent as CM (Fig. 6f).

Previous studies identified IRF7 as a limiting factor in non$\mathrm{pDC}$ models of type I IFN production ${ }^{18}$. In our hands, all pDCs displayed high levels of IRF7 immediately after isolation which decreased, however, during ex vivo culture (Supplementary Figs. 12, 13). High levels of IRF7 were induced by priming with IFN $\beta$ or by natural production of type I IFN by $\mathrm{pDCs}$ and coincided with but did not precede IFNa production (Supplementary Figs. 12, 13).

Together, these results unambiguously show that signaling via the type I IFN receptor amplifies TLR-induced IFNa production, thus modulating the patterns of heterogeneity within the $\mathrm{pDC}$ population. Next,we challenged our hypothesis that the bulk type I IFN response is governed by a small driver population of cells by conducting bulk experiments where type I IFN-mediated paracrine communication was abrogated by blocking the IFN $\alpha / \beta$ receptor and by adding neutralizing antibodies against IFNa and $-\beta$ prior to bulk activation. Our experiments revealed that blocking the IFNAR in combination 
a

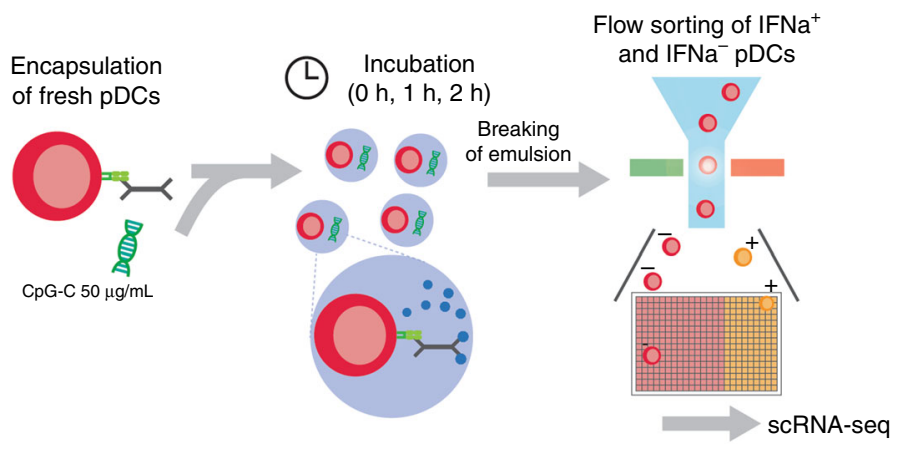

b

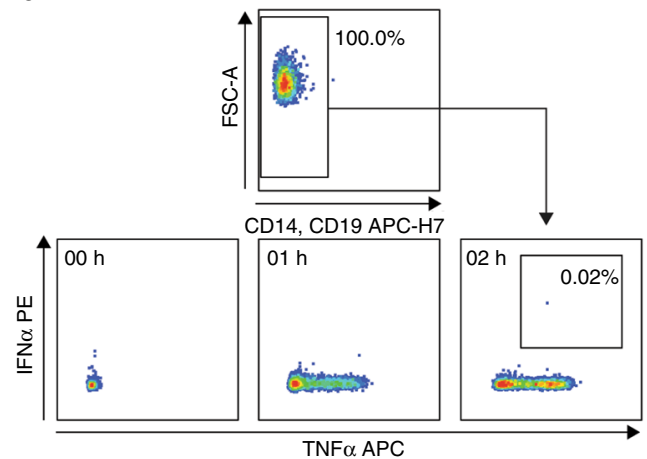

C
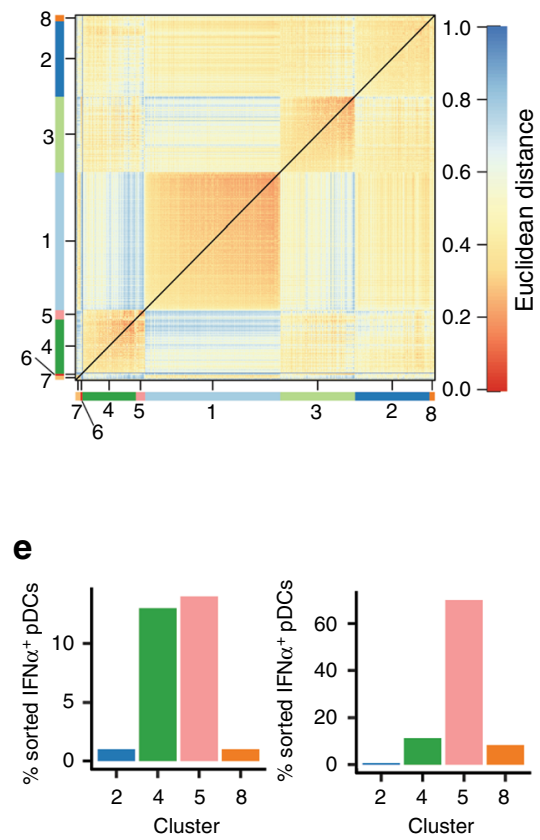

$\mathbf{f}$

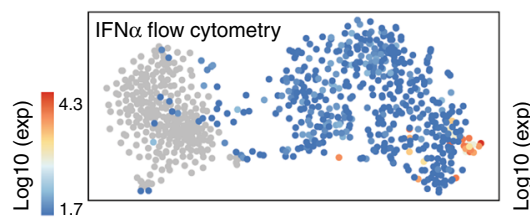

d

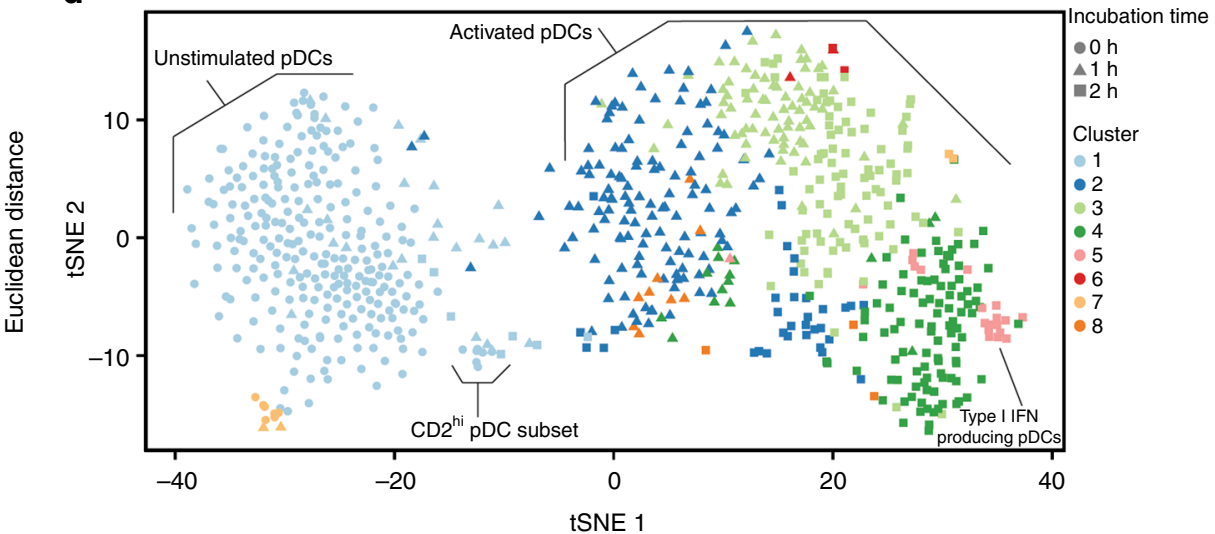

g
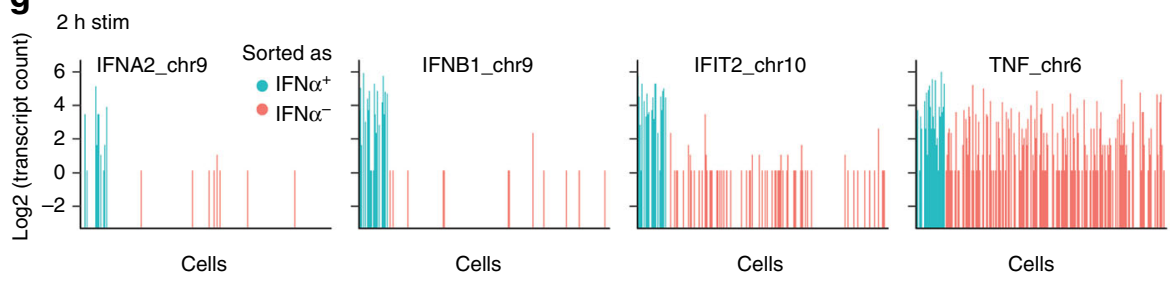

Cells

h
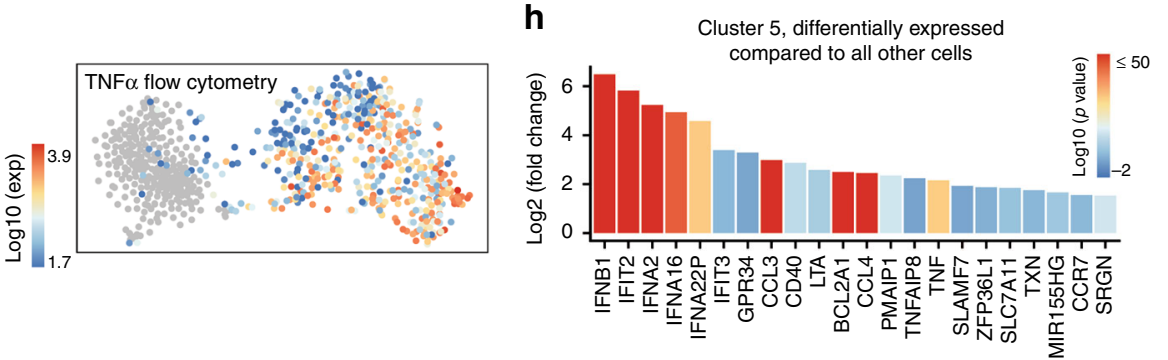

Fig. 3 Single-cell RNA-sequencing identifies type I IFN-expressing cells early after activation. a The pDCs were coated with capture reagent, encapsulated in picoliter droplets, and stimulated individually with $50 \mu \mathrm{g} / \mathrm{mL} \mathrm{CpG-C}$ for varying amounts of time. $\mathbf{b}$ After staining for surface marker expression and cytokine secretion, different pDC subsets were collected using fluorescence-activated cell sorting (FACS) and their transcriptomes were sequenced using the SORT-Seq protocol. c Heat map of the 774 cells that passed quality control filters representing transcriptome similarities as measured by Euclidean distance. The $k$-medoid clustering in combination with the raceID2 algorithm identified 8 distinct cell clusters. $\mathbf{d}$ t-SNE map showing all identified clusters. Different colors indicate clusters, different shapes indicate stimulation time. e The employed workflow allowed to link protein expression data acquired during FACS to the transcriptome data. The number of IFN $\alpha^{+}$cells assigned to each cluster, and the percentage of sorted IFN $\alpha^{+}$cells in each cluster, is plotted against the cluster name. $\mathbf{f t}$ t-SNE map showing the fluorescence intensity of IFN $\alpha$ and TNF $\alpha$ as measured during FACS for each cell. $\mathbf{g}$ Shown are transcript counts for genes of the type I IFN response and the TNF gene in single cells stimulated for $2 \mathrm{~h}$ with $\mathrm{CpG}-\mathrm{C}$. IFN $\alpha^{+}$cells, identified during FACS, are indicated in blue, other cells are shown in red. $\mathbf{h}$ Genes that were upregulated in cluster 5 compared to cells from all other clusters were detected ( $p<$ $10^{-8}$ ). Shown is the $\log 2$ (fold change) for each gene. The color scale indicates the corresponding $p$ value

with neutralizing sera reduced the fraction of cells secreting IFNa to similar numbers as observed in our droplet experiments (Supplementary Fig. 14), indicative for a pool of early responder cells.
Based on our results, we propose the following model of early pDC activation (Fig. 6g). The pDCs are able to produce IFNa constitutively, but this is a rare and stochastic process that is controlled by transcription factors such as nuclear factor (NF)- $\kappa B$ 
a

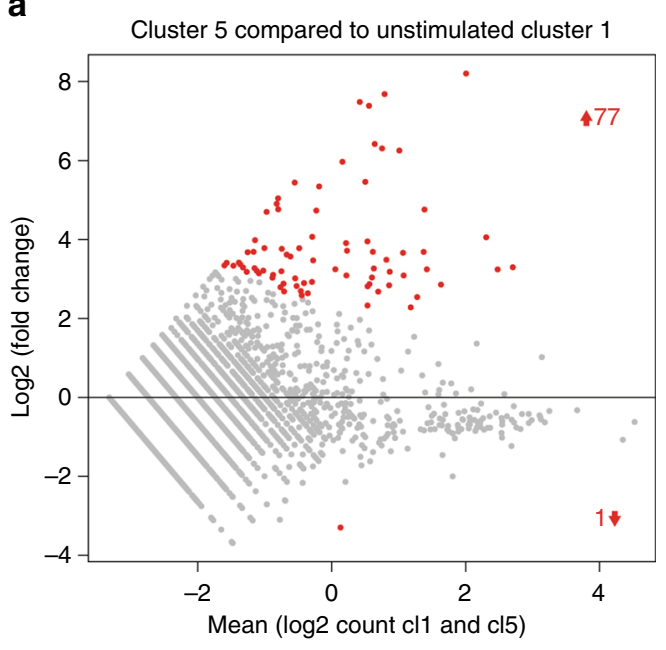

b

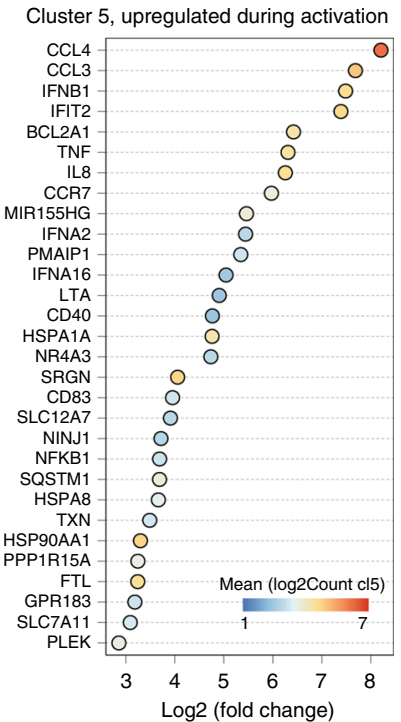

c
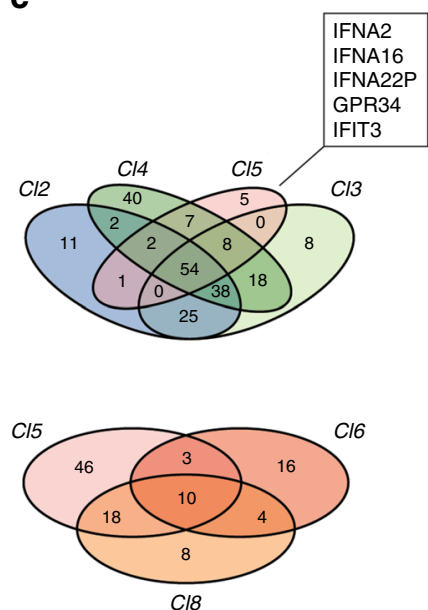

d

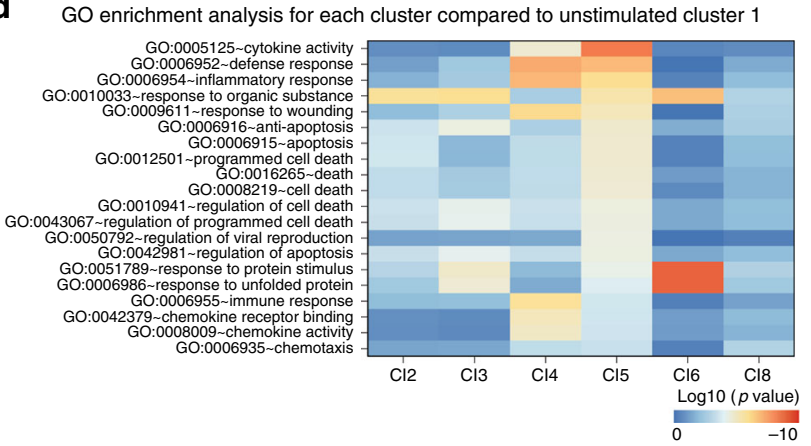

KEGG enrichment analysis for each cluster compared to unstimulated cluster 1

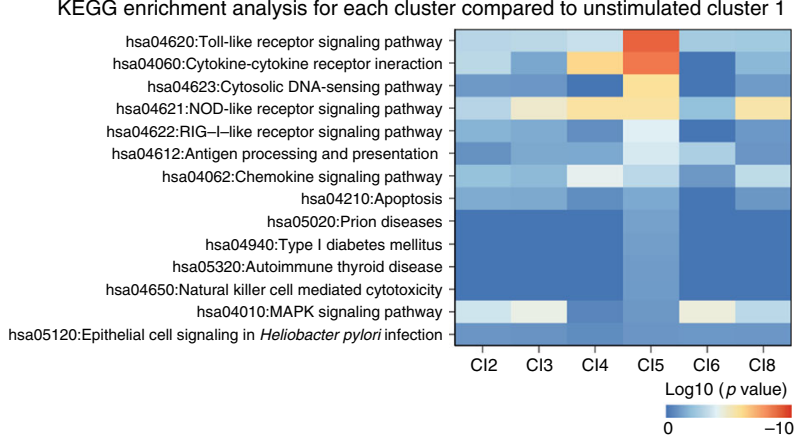

Fig. 4 Type I IFN-expressing pDCs show unique gene expression patterns. a Differentially regulated genes in cells from all activated clusters compared to cluster 1 were identified. Differentially regulated genes from cluster 5 . The average log2(count) of each gene is plotted against the log2(fold change) compared to cells in C11. Red color indicates $p$ value $<10^{-8}$. b The top 30 most upregulated genes are shown for cluster 5 . Shown is the log2 fold change for each gene. The color scale indicates the average log2(Count) for each transcript in Cl5. c Venn diagram of the upregulated genes (log2(fold change) $>1.5$, $p$ value $<10^{-8}$ ) within different clusters. $\mathbf{d}$ Lists of upregulated genes were submitted to DAVID for GO enrichment analysis and KEGG enrichment analysis. Heat maps show the most significantly enriched terms for the gene list from cluster 5 . The color scale indicates the significance of enrichment of a particular term in all selected clusters after Benjamini-Hochberg correction for multiple testing

or activator protein 1 (AP-1), but not IRF7 ${ }^{27}$. TLR triggering, which behaves as a sensitive and digital process, leads to the activation of the MyD88-IRF7 pathway and a 20-fold increase in stochastic IFNa expression. In many cells, this pathway is, however, limited by downstream components and by trafficking of CpG molecules to early endosomes. This leads to a still very limited pool of early responder pDCs that secrete type I IFN. Secreted type I IFN, then, primes surrounding pDCs and induces the expression of important factors for the IFNa production. This increases the probability of IFNa expression in those cells and leads to a robust population response.

\section{Discussion}

We show that type I IFN production by freshly isolated human pDCs is controlled by stochastic gene regulation and amplified by environmental signals. This is supported by several observations. First, TLR signaling was necessary but insufficient for the induction of type I IFN production. Only a minor subset of cells produced IFNa, whereas all cells expressed TNFa or CCR7, implying universal activation of the TLR signaling pathway. Second, neither TLR signaling strength nor duration influenced the fraction of IFNa-producing cells. Third, RNA profiling of single pDCs indicated no evidence of a privileged pDC subset with superior ability to produce type I IFN. On the contrary, a type I IFN-expressing pDC subset emerged at $2 \mathrm{~h}$ after activation, at the same time as type I IFN secretion was first observed in droplets, indicating that heterogeneity emerges simultaneously at protein and messenger RNA (mRNA) levels. Stochastic gene regulation is one of the strongest drivers of cellular heterogeneity and can be caused by not only the inherently random nature of gene expression itself but also by limitations in the signaling pathways leading to the production of a cytokine ${ }^{18,19,21,32}$. In our system, high IRF7 expression, which represented the most important cause of stochasticity in other systems, did not guarantee type I IFN production in all $\mathrm{pDCs}^{18}$.

In contrast, we show here that the microenvironment has a decisive impact on type I IFN responses as IFNa production by pDCs depended directly on cell density. This effect could be mimicked by pre-treating pDCs with type I IFN leading to an increase in the fraction of IFNa-producing individually stimulated pDCs. This combination of stochastic gene regulation and environmental response amplification poses an efficient yet 
a

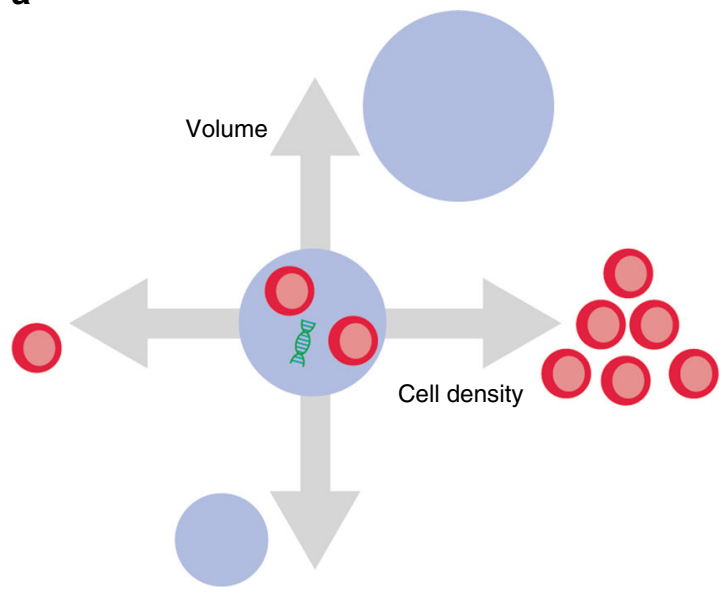

c

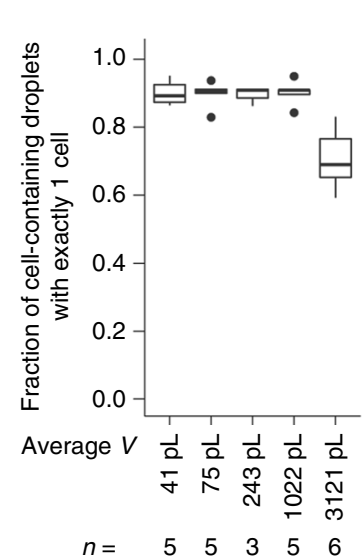

d

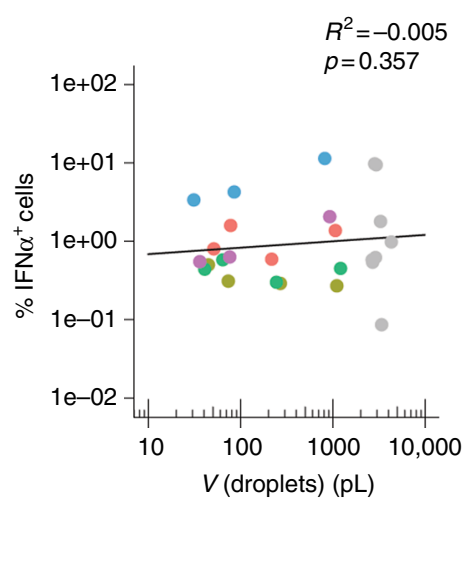

b

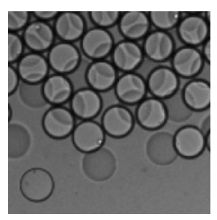

$41 \mathrm{pL}$

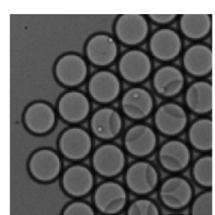

$64 \mathrm{pL}$

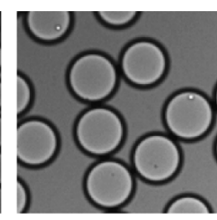

$217 \mathrm{pL}$

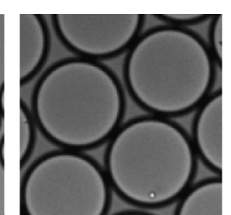

$1061 \mathrm{pL}$

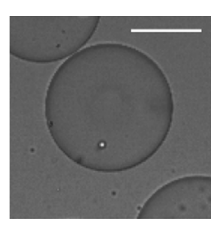

$2891 \mathrm{pL}$ e

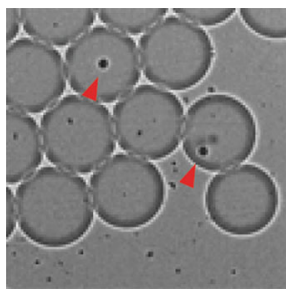

$98 \%$ single cells

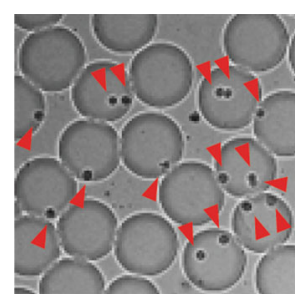

$68 \%$ single cells $\mathbf{f}$

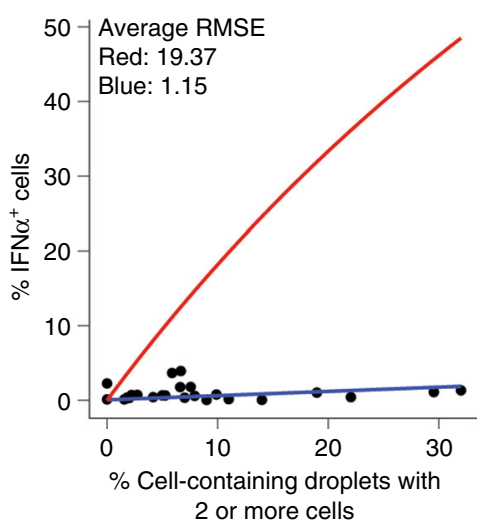

g

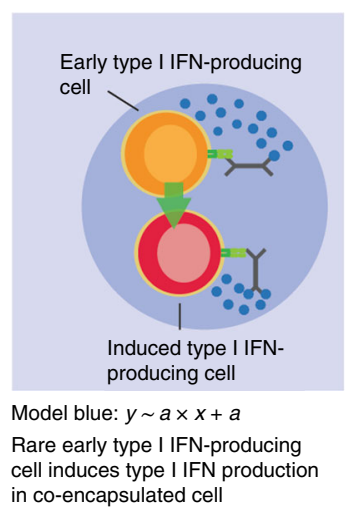

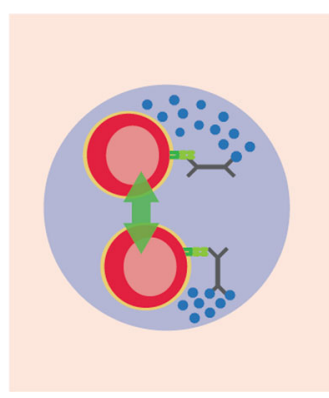

Parameters

a: Fraction of early type I IFN-producing cells that can induce type I IFN production in co-encapsulated cell

$x$ : Percentage of droplets with 2 or more cells

$y$ : Total percentage of type I IFN-producing cells

Fig. 5 Microenvironmental factors influence the fraction of IFN $\alpha$-producing pDCs. a, b The pDCs were coated with cytokine capture reagents, encapsulated in droplets of varying size (b, scale bar equals $100 \mu \mathrm{m})$, and stimulated individually with $50 \mu \mathrm{g} / \mathrm{mL} \mathrm{CpG}-\mathrm{C}$ for $12 \mathrm{~h}$. The distribution of cells in droplets was measured by manual analysis of microscopic images after production. After staining for viability and surface marker expression, viable cells and TNF $\alpha$ positive cells were detected via flow cytometry. c Shown is the fraction of cell-containing droplets with exactly one cell; $n>=3$. Lines indicate mean, hinges mark interquartile ranges, and whiskers reach to the highest/lowest value that is within $1.5 \times$ interquartile range. $\mathbf{d}$ The fraction of IFN $\alpha$-secreting pDCs was plotted against droplet volume. Dots of the same color indicate cells from the same donor. Gray dots are all originating from different donors. Linear regression was employed to calculate a trend line; $n=24$. a, e The pDCs were stimulated in $\sim 92 \mathrm{pL}$ droplets with an increasing fraction of droplets containing more than 1 cell. $\mathbf{f}$ Shown is the fraction of IFN $\alpha$-secreting cells plotted against the fraction of droplets containing more than 1 cell. Two models were generated to explain the observed pattern: (red) two random pDCs co-encapsulated in the same droplet can induce type I IFN production in each other; (blue) rare early type I IFN-producing cells can induce type I IFN production in conventional co-encapsulated cells. The root-square-mean error (RMSE) was calculated for both models to compare the fit to the data; $n=24$. $\mathbf{g}$ Schematic overview of both models

flexible solution for $\mathrm{pDCs}$ to generate robust type I IFN responses. IFNa production by rogue cells that detect hostderived nucleic acids in sterile situations is limited without type I IFN amplification, but rapid and robust responses are guaranteed when pDCs are triggered in inflamed tissue with high pDC density or type I IFN signals from infected body cells. Furthermore, controlling type I IFN production in such a populationregulated stochastic manner allows the induction of an antiviral state in all cells of a given tissue but bypasses the necessity of all cells being type I IFN producers, reducing type I IFN levels and tissue damage.

These insights have far-reaching implications: on an applied level, pDC-focused treatments, such as DC-based immunotherapy, need to reconsider vaccine parameters, such as number of injected cells, location and pre-treatment of injection side, and cell density during stimulation for better efficacy. On a more fundamental level, 
a

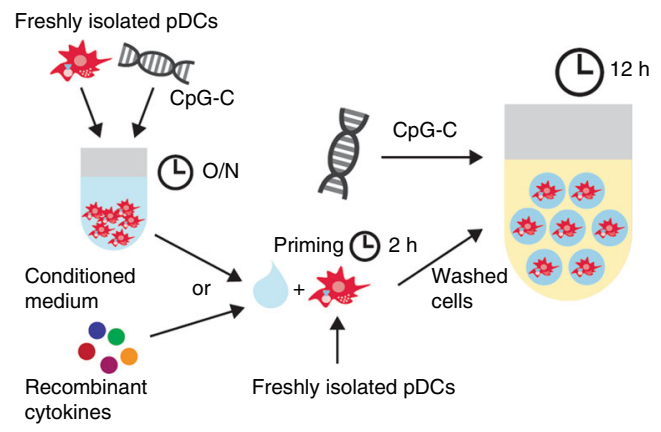

d

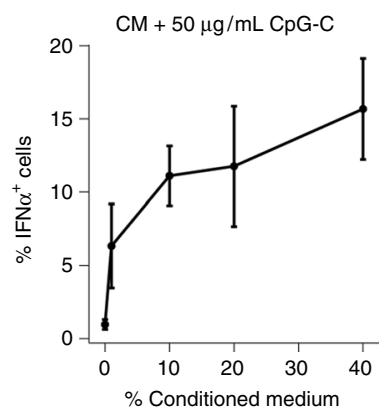

\section{$10 \% \mathrm{CM}+\mathrm{CpG}-\mathrm{C}$}

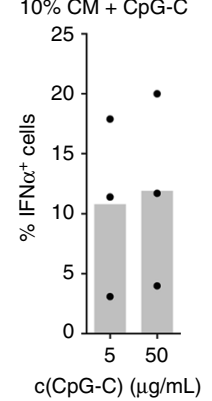

b

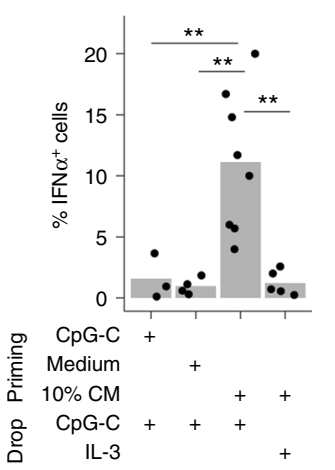

C

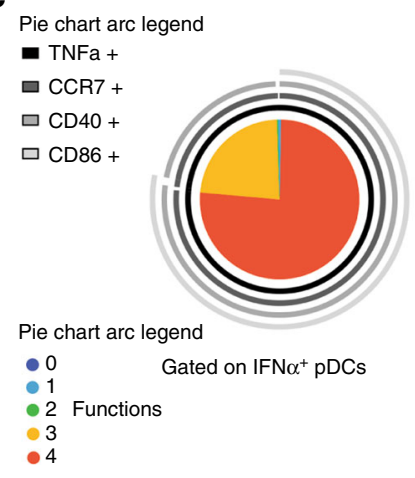

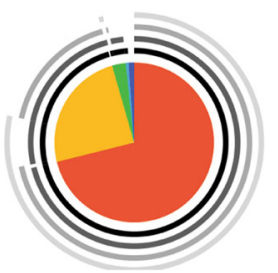

Gated on IFN $\alpha^{-}$pDCs

\section{f}

g
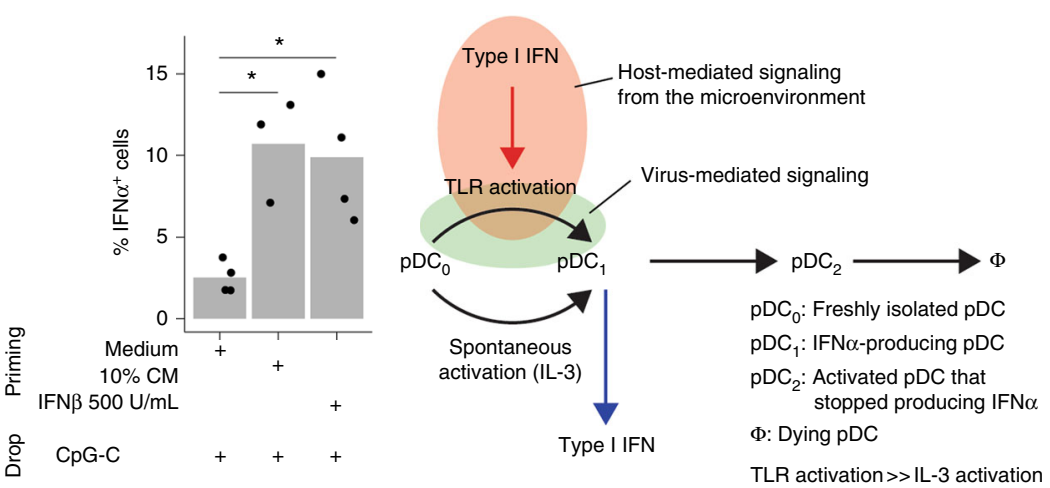

Fig. 6 The pDCs primed with CM or IFN $\beta$ are more likely to produce IFN $\alpha$. a Schematic overview of the priming experiment. The pDCs were stimulated for

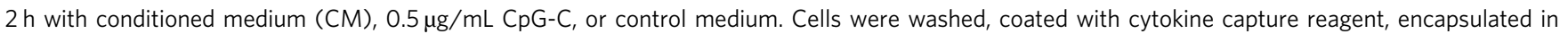
droplets, and stimulated individually with $0.01 \mu \mathrm{g} / \mathrm{mL} \mathrm{IL-3}$ or $50 \mu \mathrm{g} / \mathrm{mL} \mathrm{CpG-C}$ for $12 \mathrm{~h}$. CM was generated from bulk pDC cultures stimulated with $5 \mu \mathrm{g} /$ $\mathrm{mL} \mathrm{CpG-C}$ at a density of 25,000 cells/well. Cytokine-secreting cells were detected using flow cytometry. $\mathbf{b}$ The fraction of IFN $\alpha$-secreting cells is plotted against different treatment conditions. c Co-expression of CCR7, CD40, CD86, and TNF $\alpha$ by single IFN $\alpha^{+}$and IFN $\alpha^{-}$pDCs was analyzed. Shown is the relative contribution of each functional response pattern to the total pDC population. $\mathbf{d}$ The $\mathrm{pDC}$ s were primed with different concentrations of $\mathrm{CM}$ and

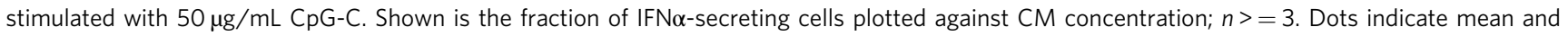
whiskers indicate SEM. e The pDCs were treated as described above, primed with $10 \% \mathrm{CM}$, and stimulated with different concentrations of $\mathrm{CpG}$-C. Shown is the fraction of IFN $\alpha$-secreting cells plotted against $\mathrm{CpG}-\mathrm{C}$ concentration; $n=3$. $\mathbf{f}$ The pDCs were primed with $10 \% \mathrm{CM}$, control medium, or $500 \mathrm{U} / \mathrm{mL}$

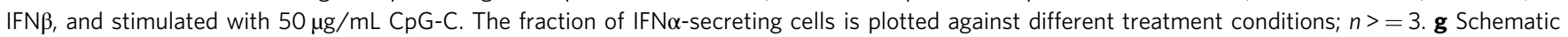
model illustrating stochastic IFN $\alpha$-production by $\mathrm{pDCs}$. Few pDCs produce IFN $\alpha$ constitutively without stimulation by TLR ligands, here resembled by differentiation from a freshly isolated $\mathrm{pDC}\left(\mathrm{pDC} \mathrm{C}_{0}\right)$ to an IFN $\alpha$-secreting $\mathrm{pDC}\left(\mathrm{pDC}_{1}\right)$. Literature indicates that this is not IRF7 dependent but NF- $\mathrm{kB}$ and $\mathrm{AP}$ 127. Upon TLR9 triggering the IRF7-dependent pathway is activated which also allows differentiation to IFN $\alpha$-secreting pDC at a much higher rate. Despite involvement of the IRF7 pathway, still only very few pDCs produce IFN $\alpha$. Paracrine signaling via the type I IFN receptor can increase this rate, probably via the upregulation of IRF7 expression, leading to a large fraction of cells expressing IFN $\alpha$. After producing IFN $\alpha$, pDCs become refractory to re-stimulation $\left(\mathrm{pDC}_{2}\right)$ and eventually die $(\Phi)$. b, f Welch-corrected two-sample $t$-test; ${ }^{*} p<0.05,{ }^{\star *} p<0.01$

our insights imply that the functional behavior of pDCs is plastic and adaptable to local cues from the tissue microenvironment, similar to macrophages ${ }^{42}$. Therapy approaches that target pDCs inside the body should take into account that not all pDCs are the same and that pDCs might react differently to treatment depending on the tissue context of the disease.

Here, we show that well-studied human primary immune cell responses can be based on stochastic processes at the single-cell level and emphasize the importance of single-cell techniques to deconstruct immunological responses at the single-cell level.

\section{Methods}

Antibodies and cell stimuli. For a full list of utilized antibodies and reagents, the readers are referred to the Supplementary Methods.

Cell isolation and culture. Jurkat T cells (ATCC, Clone E6-1 (ATCC ${ }^{\circledast}$ TIB-152 ${ }^{\text {'tw }}$ )) were cultured in RPMI (Thermo Fischer Scientific) supplemented with $10 \%$ fetal calf serum (FCS; Greiner Bio-One) and 1\% Antibiotic-Antimycotic (Life Technologies), and regularly tested for mycoplasma contamination. The pDCs were obtained from buffy coats of healthy donors (Sanquin) after written informed consent per the Declaration of Helsinki and according to institutional guidelines. In short, peripheral blood mononuclear cells (PBMCs) were isolated from donor blood via Ficoll density gradient centrifugation (Axis-Shield). The pDCs were subsequently isolated using magnet-activated cell sorting (MACS) or fluorescenceactivated cell sorting (FACS).

For MACS isolation, PBMCs were resuspended in X-Vivo 15 cell culture medium (Lonza) supplemented with $2 \%$ pooled human serum (HS; Sanquin) and incubated for $1 \mathrm{~h}$ at $37^{\circ} \mathrm{C}$ in cell culture flasks T75 (Corning) to deplete monocytes. Cells were washed thrice with phosphate-buffered saline (PBS; Braun) while nonadherent cells were collected. The pDCs were isolated from this cell population by positive selection using the CD304 Microbeat Kit (Miltenyi Biotec) following the manufacturer's instructions. Cells were counted and purity was assessed using flow cytometry. For this purpose, cells were washed with PBS supplemented with $0.5 \%$ bovine serum albumin fraction $\mathrm{V}$ (BSA, Roche) and $0.01 \% \mathrm{NaN}_{3}$ (Merck; subsequently referred to as PBA) and stained for $10 \mathrm{~min}$ at $4{ }^{\circ} \mathrm{C}$ using APC-labeled anti-CD303 and fluorescein isothiocyanate (FITC)-labeled anti-Lineage Cocktail 1 (LIN1) antibodies in $30 \mu \mathrm{L}$ PBA. The pDCs were identified as $\mathrm{CD}_{303}{ }^{+} \mathrm{LIN}^{-}$and purity was on average $93 \%$ (Std.: $3.76 \%, n=67$ ).

For FACS isolation, PBMCs were washed and FITC-labeled anti-LIN1 antibodies were added to the pellet. Cells were incubated for $20 \mathrm{~min}$ at $4{ }^{\circ} \mathrm{C}$. Subsequently, cells were washed with PBS supplemented with $4 \mathrm{mM}$ 
ethylenediaminetetraacetic acid (EDTA; Sigma) and 0.1\% BSA (subsequently referred to as wash buffer) and anti-FITC microbeads (Miltenyi Biotec) were added to the pellet. Cells were incubated for $30 \mathrm{~min}$ at $4{ }^{\circ} \mathrm{C}$ and subsequently washed with wash buffer. LIN1-positive cells were magnetically depleted using an LD column (Miltenyi Biotec) following the manufacturer's instructions. Cells were washed with wash buffer and VioBlue- or PE-Cy7-labeled anti-HLA-DR and BV510- or PElabeled anti-CD304 antibodies were added to the pellet. Cells were incubated for $30 \mathrm{~min}$ at $4{ }^{\circ} \mathrm{C}$ and afterwards washed with wash buffer. The pDCs were sorted as LIN $1^{-}$HLA-DR ${ }^{+} \mathrm{CD} 304^{+}$cells on a FACS Aria II SORP (BD).

During stimulation, pDCs were cultured in X-Vivo 15 supplemented with $2 \%$ HS or RPMI supplemented with $10 \%$ FCS.

Soft lithographic procedure. The microfluidic device was molded against an SU-8 photo resist structure on a silicon wafer using a commercially available polydimethylsiloxane silicone elastomer (Sylgard 184, Dow Corning). The surface of the Sylgard 184 was $\mathrm{OH}$-terminated by exposure to plasma (Diener Electronic $\mathrm{GmbH}$ ), and was sealed with another plasma-treated glass cover slide to yield closed micro channels. Channels were treated with a $2 \%$ silane solution.

Microfluidic setup. Soft lithographic techniques were used to fabricate microfluidic channels (see above). Liquids were dispensed from plastic syringes (Becton Dickinson), which were connected to the microfluidic device by polytetrafluoroethylene tubing (Novodirect $\mathrm{GmbH}$ ). The syringes were driven by computercontrolled syringe pumps (Nemesys, Cetoni $\mathrm{GmbH}$ ). For the stability of droplets, $3 \mathrm{w} / \mathrm{w} \%$ Pico-Surf ${ }^{\circledast}$ surfactant (Sphere Fluidics) was used in fluorinated HFE-7500 oil (Novec 7500, 3M). Cells and stimuli were loaded separately on the microfluidic chip. The dimensions of the microfluidic channels are $40 \mu \mathrm{m} \times 25 \mu \mathrm{m}$ at the first inlet, $60 \mu \mathrm{m} \times 25 \mu \mathrm{m}$ at the second inlet and the production nozzle, and $100 \mu \mathrm{m} \times$ $25 \mu \mathrm{m}$ at the collection channel.

Priming and blocking. To block type I IFN signaling, pDCs were incubated at $37^{\circ} \mathrm{C}$ for 30 min with medium containing blocking antibody against IFNAR2 (PBL Assay Science, $10 \mu \mathrm{g} / \mathrm{mL}$ ) and neutralizing sera against IFNa and IFN $\beta$ (both from PBL Biomedical Laboratories, both $1000 \mathrm{NU} / \mathrm{mL}$ ). To prime, pDCs were resuspended in medium containing cytokines or conditioned medium and incubated for $2 \mathrm{~h}, 37^{\circ} \mathrm{C}$. Subsequently, cells were washed thrice with wash buffer and prepared for downstream applications.

Single-cell activation assay. Cells were washed twice with wash buffer and incubated in $100 \mu \mathrm{L}$ per $10^{6}$ cells wash buffer containing Cytokine Catch Reagent (Miltenyi Biotec) at $4^{\circ} \mathrm{C}$ for at least $40 \mathrm{~min}$. Control experiments excluded that the employed Cytokine Catch Reagents affect viability or cellular functions (Supplementary Fig. 15). Next, cells were washed with wash buffer and medium and resuspended in medium at $2.6 \cdot 10^{6}$ cells $/ \mathrm{mL}$ for single-cell encapsulation in $70-100 \mathrm{pL}$ droplets. In case of experiments using different droplet sizes or multiple cells per drop, these concentrations were adjusted to yield the desired Poisson distribution. Stimulus was dissolved in medium at twice the desired concentration to account for on-Chip dilution. For $90 \mathrm{pL}$ droplet production, flow rates were adjusted to $900 \mu \mathrm{L} / \mathrm{h}$ for the oil phase and $200 \mu \mathrm{L} / \mathrm{h}$ for the aqueous fractions (Supplementary Table 4 for overview of all employed flow rates). In all experiments, constant volumetric flow rates were used. To assess the encapsulation rate, videos of the droplet production and images of the produced emulsion were acquired using a CKX41 microscope (Olympus) at $\times 10$ magnification. Encapsulation rate was manually assessed using $\mathrm{Fiji}^{43,44}$. The emulsion was collected and covered with medium to protect droplets from evaporation. Cells were incubated with open lid at $37^{\circ} \mathrm{C}$ and $5 \% \mathrm{CO}_{2}$. Next, the emulsion was broken by adding $150 \mu \mathrm{L}$ HFE-7500 containing $20 \% \mathrm{w} / \mathrm{w} 1 \mathrm{H}, 1 \mathrm{H}, 2 \mathrm{H}, 2 \mathrm{H}$-Perfluoro-1-octanol and centrifuging briefly at 60 relative centrifugal force (RCF). The cell-containing aqueous phase was transferred into a new tube containing $500 \mu \mathrm{L}$ PBA and left for 2 min to allow residual oil to settle. Finally, the aqueous phase was transferred into a clean tube and cells were washed with PBS. Dead cells were identified by staining with Fixable Viability Dye eFluor ${ }^{\circledR} 780$ (eBioscience, 1:2000 in PBS, $100 \mu \mathrm{L}$ ) for 30 min at $4{ }^{\circ} \mathrm{C}$. Cells were washed once with PBS and blocked with PBA supplemented with $1 \% \mathrm{HS}$ for $10 \mathrm{~min}$ at $4{ }^{\circ} \mathrm{C}$. To stain for surface proteins and captured cytokines, cells were incubated with antibodies in $70 \mu \mathrm{L}$ PBA supplemented with $1 \% \mathrm{HS}$ for $10 \mathrm{~min}$ on ice. After incubation, cells were washed and resuspended in PBA and kept at $4{ }^{\circ} \mathrm{C}$ until acquisition on a FACS Verse flow cytometer (BD).

RNA isolation and quantitative PCR. RNA was isolated using Trizol (Life Technologies) following the manufacturer's protocol. RNA quantity was determined on NanoDrop 2000c (Thermo Scientific) and RNA quality was determined via agarose gel electrophoresis. Then, $2 \mu \mathrm{g}$ of RNA was DNAse I-treated to remove residual genomic DNA and reverse transcribed into complementary DNA (cDNA) by M-MLV reverse transcriptase (Life Technologies) to obtain $25 \mu \mathrm{L}$ of cDNA. The cDNA was diluted $25 \times$ in nuclease free water. For each reaction, $4 \mu \mathrm{L}$ diluted cDNA, $300 \mathrm{nM}$ primers, $10 \mu \mathrm{L}$ SYBR Green (Roche), and water were added to a final volume of $20 \mu \mathrm{L}$. Each sample was amplified using a CFX96 sequence detection system (Bio-Rad). The following quantitative PCR (qPCR) cycling conditions were used: $50^{\circ} \mathrm{C} / 2 \mathrm{~min}, 95^{\circ} \mathrm{C} / 10 \mathrm{~min}, 40$ cycles of $95^{\circ} \mathrm{C} / 15 \mathrm{~s} ; 60^{\circ} \mathrm{C} / 1 \mathrm{~min}$, melt analysis $60^{\circ} \mathrm{C}-95^{\circ} \mathrm{C}$ with increment $0.5^{\circ} \mathrm{C} / 5 \mathrm{~s}$. The gene-specific oligonucleotide primers used to determine the expression of the genes of interest are listed in Supplementary Table 2. To increase the chance of consistency, qPCR primers were based on the MA probes with highest differential expression. PCR products were monitored by measuring the increase of fluorescence caused by binding of SYBR Green. Quantitative PCR data were analyzed using CFX96 manager and relative expression of the gene of interest was determined using the cycle threshold method with GAPDH as reference genes ${ }^{45}$.

Perturbation profiling-scRNA-seq. Using FACS as described above, single cells were sorted in 384-well plates containing a $50 \mathrm{~nL}$ droplet with CELseq2-primers and covered by mineral oil. A Mosquito ${ }^{\circledast}$ HTS (TTP Labtech) was used to dispense the droplets. To remove red blood cells, PBMCs were resuspended in $8 \mathrm{~mL}$ of icecold ACK buffer and incubated for 5 min on ice prior antibody staining with FITClabeled anti-LIN1. Subsequently, the cells were washed with X-Vivo 15 supplemented with $2 \%$ HS and the standard protocol was further followed.

After sorting, plates were immediately frozen at $-80^{\circ} \mathrm{C}$ until further processing. Several days later, plates were thawed and incubated at $65^{\circ} \mathrm{C}$ for $5 \mathrm{~min}$ to lyse cells Perturbation profiling was conducted using the SORT-Seq protocol ${ }^{33}$. In short, spike-in RNA, reverse transcriptase and second-strand mixes were added to the wells using the Nanodrop II liquid handling platform (GC Biotech). Subsequently, the mRNA of each cell was reverse transcribed and converted to double-stranded cDNA. Libraries were then pooled, and in vitro transcribed for linear amplification, following the CEL-Seq 2 protocol $^{46}$. Primers consisted of a 24 bp polyT stretch, a 6 bp random molecular barcode (unique molecular identifier (UMI)), a cell-specific 8 bp barcode, the $5^{\prime}$ Illumina TruSeq small RNA kit adaptor, and a T7 promoter Illumina sequencing libraries were then prepared with the TruSeq small RNA primers (Illumina) and sequenced paired-end at $75 \mathrm{bp}$ read length (high output) on the Illumina NextSeq.

Stimulation in microtiter plate. The pDCs were resuspended in $100 \mu \mathrm{L}$ medium containing the appropriate stimulus (see supplementary methods) and cultured in 96-well round bottom plates (Costar, polystyrene) at a density of 25,000 cells per well if not stated differently. Depending on the experimental setting, Brefeldin A (Sigma, $10 \mu \mathrm{g} / \mathrm{mL}$ ) was added $2 \mathrm{~h}$ before harvesting the cells.

Antibody staining. Cells were washed once with PBS and dead cells were identified by staining with Fixable Viability Dye eFluor ${ }^{\circledR} 780$ (eBioscience, 1:2000 in PBS, $100 \mu \mathrm{L}$ ) at $4^{\circ} \mathrm{C}$ for $30 \mathrm{~min}$. Subsequently, cells were washed once with PBS and blocked with PBA supplemented with $1 \% \mathrm{HS}$ at $4{ }^{\circ} \mathrm{C}$ for $10 \mathrm{~min}$. Cells were washed and incubated with antibodies against surface proteins in $30 \mu \mathrm{L}$ PBA supplemented with $1 \% \mathrm{HS}$ for $10 \mathrm{~min}$ on ice. Afterwards, cells were washed with PBA followed by a wash with PBS. Cells were fixed and permeabilized with Cytofix/Cytoperm solution (BD, $100 \mu \mathrm{L}$ ) for $20 \mathrm{~min}$ at $4^{\circ} \mathrm{C}$. Next, cells were washed with Perm/Wash buffer (BD) and blocked for $10 \mathrm{~min}$ at $4^{\circ} \mathrm{C}$ using Perm/Wash buffer supplemented with $1 \%$ HS. Subsequently, cells were incubated with antibodies against intracellular proteins in $30 \mu \mathrm{L}$ Perm/Wash buffer supplemented with $1 \% \mathrm{HS}$ for $30 \mathrm{~min}$ at $4{ }^{\circ} \mathrm{C}$. Cells were washed twice with Perm/Wash buffer followed by a wash with PBA and resuspended in PBA. For IRF7 staining, cells were instead fixed with $4 \%$ paraformaldehyde (Merck) in PBS for 10 min at room temperature. After incubation, PBA was added and cells were washed twice with PBA, followed by a wash with PBA supplemented with $0.1 \%$ Triton X (Sigma). Cells were blocked for $10 \mathrm{~min}$ at $4{ }^{\circ} \mathrm{C}$ using PBA supplemented with $0.1 \%$ Triton $\mathrm{X}$ and $1 \% \mathrm{HS}$. Subsequently, cells were incubated with antibodies against intracellular proteins in $30 \mu \mathrm{L}$ PBA supplemented with $0.1 \%$ Triton X and $1 \% \mathrm{HS}$ for $30 \mathrm{~min}$ at $4{ }^{\circ} \mathrm{C}$. Cells were washed twice with PBA supplemented with $0.1 \%$ Triton $\mathrm{X}$ followed by a wash with PBA and resuspended in PBA. All cells were kept at $4^{\circ} \mathrm{C}$ until acquisition on a FACS Verse flow cytometer (BD). To guarantee highest purity in experiments, we limited our analysis to viable $\mathrm{CD} 14^{-} \mathrm{CD} 19^{-} \mathrm{pDCs}$.

ELISA analysis. The enzyme-linked immunosorbent assay (ELISA) plates (Nunc MaxiSorp ELISA Plates for IFNa, Greiner bio-one high binding microplates for TNFa ELISA) were incubated with PBS containing anti-cytokine antibodies at the manufacturer-recommended concentration (Human IFN-alpha matched antibody pairs, Human TNF alpha ELISA Ready-SET-Go, both from eBioscience) overnight at $4{ }^{\circ} \mathrm{C}$. Next, plates, coated with antibodies against IFNa, were washed once with PBS supplemented with $0.05 \%$ Tween-20 (Merck, subsequently referred to as ELISA wash buffer and used for all wash steps) and blocked using $250 \mu \mathrm{L}$ ELISA wash buffer supplemented with $0.5 \%$ BSA for $2 \mathrm{~h}$ at room temperature. Plates were washed twice and incubated with $50 \mu \mathrm{L}$ of sample or standard and $50 \mu \mathrm{L}$ of horseradish peroxidase (HRP)-conjugated detection antibody at the recommended concentration for $2 \mathrm{~h}$ at room temperature. Plates coated with antibodies against TNFa were washed once and blocked with ELISA dilutent (eBioscience) for $2 \mathrm{~h}$ at room temperature. Plates were washed once and incubated with $50 \mu \mathrm{L}$ sample or standard. Next, plates were washed $4 \times$ and incubated with detection antibody at the recommended concentration. Subsequently, plates were washed $4 \times$ and incubated with Avidin-HRP at the recommended concentration for $30 \mathrm{~min}$ at room temperature. Finally, all plates were washed trice and incubated with $100 \mu \mathrm{L}$ TMB 
Solution (eBioscience). Reaction was stopped by adding $100 \mu \mathrm{L}$ of $1 \mathrm{M} \mathrm{H}_{3} \mathrm{PO}_{4}$ and absorption was measured at $450 \mathrm{~nm}$ using a microplate reader (Bio-Rad).

Flow cytometry and ELISA analysis. Flow cytometry data were analyzed using FlowJo X (Tree Star) and SPICE (downloaded from http://exon.niaid.nih.gov) ${ }^{47}$. Analysis and presentation of distributions was performed using PRISM for windows version 5.03 (GraphPad) and The R Project for Statistical Computing using the ggplot2, reshape, and xlsx packages ${ }^{48-51}$. For statistical analysis, Student's $t$-test, Mann-Whitney test, and linear regression analysis using least square fit were performed.

Linear regression model. Two models were generated: direct interactions between two random pDCs amplify the type I IFN production $(2 \times$ percentage of droplets with $>1$ cells $/[100 \%+$ percentage of droplets with $>1$ cells $] \times 100 \% \sim$ percentage of cells that produce IFNa); interactions between early type I IFN-producing pDCs and other pDCs amplify type I IFN production (percentage of droplets $>1$ cells . percentage of early-responding cells + the percentage of early-responding cells percentage of cells that produce IFNa). In both models, droplets with 3 or more cells are treated as if they contained only 2 cells. To compare the fit of each model, the dataset $(n=24)$ was randomly split into training $(75 \%)$ and test $(25 \%)$. Model parameters were estimated based on the training dataset, and the test dataset was used to predict the fraction of type I IFN-producing cells. Predicted and measured values were compared using the root-mean-square error (RMSE). This process was repeated 100 times and the average RMSE for each model was calculated.

ScRNA-seq analysis. Paired-end reads from Illumina sequencing were aligned to the human transcriptome with BWA $^{52}$. Read 1 was used for assigning reads to correct cells and libraries, while read 2 was mapped to gene models. Reads that mapped equally well to multiple locations were discarded. Read counts were first corrected for UMI barcode by removing duplicate reads that had identical combinations of library, cellular, and molecular barcodes and were mapped to the same gene. Transcript counts were then adjusted to the expected number of molecules based on counts, 4096 possible UMIs, and poissonian counting statistics.

Samples were normalized by down-sampling to a minimum number of 1700 transcripts. RaceID2 was used to cluster cells and to perform outlier analysis. Differentially expressed genes between two subgroups of cells were identified based on DEseq ${ }^{33}$. Gene ontology (GO) and KEGG (Kyoto Encyclopedia of Genes and Genomes) analysis was conducted by submitting lists of up to 50 most upregulated genes (log2 (fold change) of $>1.5$, adjusted $p$ value $<10^{-8}$ ) to the DAVID 6.7 online platform 40,41

Data availability. All relevant data related to this manuscript are available on request from the authors. The accession number for the single-cell RNA-sequencing data described in this study is GEO: GSE114161. All relevant codes related to this manuscript are available from the authors or as Supplementary Information.

Received: 29 December 2017 Accepted: 25 July 2018

Published online: 20 August 2018

\section{References}

1. Siegal, F. P. et al. The nature of the principal type 1 interferon-producing cells in human blood. Science 284, 1835-1837 (1999).

2. Cella, M. et al. Plasmacytoid monocytes migrate to inflamed lymph nodes and produce large amounts of type I interferon. Nat. Med. 5, 919-923 (1999).

3. Swiecki, M. \& Colonna, M. The multifaceted biology of plasmacytoid dendritic cells. Nat. Rev. Immunol. 15, 471-485 (2015).

4. Barrat, F. J. et al. Nucleic acids of mammalian origin can act as endogenous ligands for Toll-like receptors and may promote systemic lupus erythematosus. J. Exp. Med. 202, 1131-1139 (2005).

5. Means, T. K. et al. Human lupus autoantibody-DNA complexes activate DCs through cooperation of CD32 and TLR9. J. Clin. Invest. 115, 407-417 (2005).

6. Menon, M., Blair, P. A., Isenberg, D. A. \& Mauri, C. A regulatory feedback between plasmacytoid dendritic cells and regulatory B cells is aberrant in systemic lupus erythematosus. Immunity 44, 683-697 (2016).

7. Kranz, L. M. et al. Systemic RNA delivery to dendritic cells exploits antiviral defence for cancer immunotherapy. Nature 534, 396-401 (2016).

8. Tel, J. et al. Natural human plasmacytoid dendritic cells induce antigen-specific T-cell responses in melanoma patients. Cancer Res. 73, 1063-1075 (2013)

9. Kadowaki, N., Antonenko, S. \& Liu, Y. J. Distinct CpG DNA and polyinosinicpolycytidylic acid double-stranded RNA, respectively, stimulate CD11c(-) type 2 dendritic cell precursors and $\mathrm{CD} 11 \mathrm{c}(+)$ dendritic cells to produce type I IFN. J. Immunol. 166, 2291-2295 (2001).
10. Lund, J. M. et al. Recognition of single-stranded RNA viruses by Toll-like receptor 7. Proc. Natl Acad. Sci. USA 101, 5598-5603 (2004).

11. Dai, J. H., Megjugorac, N. J., Amrute, S. B. \& Fitzgerald-Bocarsly, P. Regulation of IFN regulatory factor-7 and IFN-alpha production by enveloped virus and lipopolysaccharide in human plasmacytoid dendritic cells. J. Immunol. 173, 1535-1548 (2004)

12. Zhang, $H$. et al. A distinct subset of plasmacytoid dendritic cells induces activation and differentiation of B and T lymphocytes. Proc. Natl Acad. Sci. USA 114, 1988-1993 (2017).

13. Matsui, T. et al. CD2 distinguishes two subsets of human plasmacytoid dendritic cells with distinct phenotype and functions. J. Immunol. 182, 6815-6823 (2009).

14. Zhang, X. et al. Neonatal plasmacytoid dendritic cells (pDCs) display subset variation but can elicit potent anti-viral innate responses. PLoS ONE 8, e52003 (2013)

15. Villani, A. C. et al. Single-cell RNA-seq reveals new types of human blood dendritic cells, monocytes, and progenitors. Science 356, pii: eaah4573 (2017).

16. See, P. et al. Mapping the human DC lineage through the integration of highdimensional techniques. Science 356, pii: eaag3009 (2017).

17. Patil, S. et al. Single-cell analysis shows that paracrine signaling by first responder cells shapes the interferon-beta response to viral infection. Sci. Signal. 8, ra16 (2015).

18. Zhao, M., Zhang, J., Phatnani, H., Scheu, S. \& Maniatis, T. Stochastic expression of the interferon-beta gene. PLoS Biol. 10, e1001249 (2012)

19. $\mathrm{Hu}, \mathrm{J}$. et al. Role of cell-to-cell variability in activating a positive feedback antiviral response in human dendritic cells. PLoS ONE 6, e16614 (2011).

20. Shalek, A. K. et al. Single-cell RNA-seq reveals dynamic paracrine control of cellular variation. Nature 510, 363-369 (2014)

21. Rand, U. et al. Multi-layered stochasticity and paracrine signal propagation shape the type-I interferon response. Mol. Syst. Biol. 8, 584 (2012).

22. Gary-Gouy, H., Lebon, P. \& Dalloul, A. H. Type I interferon production by plasmacytoid dendritic cells and monocytes is triggered by viruses, but the level of production is controlled by distinct cytokines. J. Interf. Cytok Res 22, 653-659 (2002).

23. Cao, W. P. et al. Toll-like receptor-mediated induction of type I interferon in plasmacytoid dendritic cells requires the rapamycin-sensitive PI(3) K-mTORp70S6K pathway. Nat. Immunol. 9, 1157-1164 (2008).

24. Guiducci, C. et al. PI3K is critical for the nuclear translocation of IRF-7 and type I IFN production by human plasmacytoid predendritic cells in response to TLR activation. J. Exp. Med. 205, 315-322 (2008).

25. Shinohara, M. L. et al. Osteopontin expression is essential for interferon-alpha production by plasmacytoid dendritic cells. Nat. Immunol. 7, 498-506 (2006)

26. Marie, I., Durbin, J. E. \& Levy, D. E. Differential viral induction of distinct interferon-alpha genes by positive feedback through interferon regulatory factor-7. EMBO J. 17, 6660-6669 (1998).

27. Kim, S. et al. Self-priming determines high type I IFN production by plasmacytoid dendritic cells. Eur. J. Immunol. 44, 807-818 (2014).

28. Macosko, E. Z. et al. Highly parallel genome-wide expression profiling of individual cells using nanoliter droplets. Cell 161, 1202-1214 (2015).

29. Lan, F., Demaree, B., Ahmed, N. \& Abate, A. R. Single-cell genome sequencing at ultra-high-throughput with microfluidic droplet barcoding. Nat. Biotechnol. 35, 640-646 (2017).

30. Chokkalingam, V. et al. Probing cellular heterogeneity in cytokine-secreting immune cells using droplet-based microfluidics. Lab Chip 13, 4740-4744 (2013).

31. Mazutis, L. et al. Single-cell analysis and sorting using droplet-based microfluidics. Nat. Protoc. 8, 870-891 (2013).

32. Raj, A. \& van Oudenaarden, A. Nature, nurture, or chance: stochastic gene expression and its consequences. Cell 135, 216-226 (2008).

33. Muraro, M. J. et al. A single-cell transcriptome atlas of the human pancreas. Cell Syst. 3, 385-394 (2016).

34. Grun, D. et al. Single-cell messenger RNA sequencing reveals rare intestinal cell types. Nature 525, 251-255 (2015).

35. Saito, K. et al. Heat shock protein 90 associates with Toll-like receptors $7 / 9$ and mediates self-nucleic acid recognition in SLE. Eur. J. Immunol. 45, 2028-2041 (2015)

36. Jacquemin, C. et al. HSP70 potentiates interferon-alpha production by plasmacytoid dendritic cells: relevance for cutaneous lupus and vitiligo pathogenesis. Br. J. Dermatol. 177, 1367-1375 (2017).

37. Elton, T. S., Selemon, H., Elton, S. M. \& Parinandi, N. L. Regulation of the MIR155 host gene in physiological and pathological processes. Gene 532, 1-12 (2013).

38. Brewitz, A. et al. CD8+T cells orchestrate pDC-XCR1+dendritic cell spatial and functional cooperativity to optimize priming. Immunity 46, 205-219 (2017).

39. Facchetti, F., Vermi, W., Mason, D. \& Colonna, M. The plasmacytoid monocyte/interferon producing cells. Virchows Arch. 443, 703-717 (2003).

40. Huang da, W., Sherman, B. T. \& Lempicki, R. A. Systematic and integrative analysis of large gene lists using DAVID bioinformatics resources. Nat. Protoc. 4, 44-57 (2009). 
41. Huang da, W., Sherman, B. T. \& Lempicki, R. A. Bioinformatics enrichment tools: paths toward the comprehensive functional analysis of large gene lists. Nucleic Acids Res. 37, 1-13 (2009).

42. Okabe, Y. \& Medzhitov, R. Tissue biology perspective on macrophages. Nat. Immunol. 17, 9-17 (2016).

43. Schneider, C. A., Rasband, W. S. \& Eliceiri, K. W. NIH Image to ImageJ: 25 years of image analysis. Nat. Methods 9, 671-675 (2012).

44. Schindelin, J. et al. Fiji: an open-source platform for biological-image analysis. Nat. Methods 9, 676-682 (2012).

45. Livak, K. J. \& Schmittgen, T. D. Analysis of relative gene expression data using real-time quantitative PCR and the 2(T)(-Delta Delta C) method. Methods 25, 402-408 (2001).

46. Hashimshony, T. et al. CEL-Seq2: sensitive highly-multiplexed single-cell RNA-Seq. Genome Biol. 17, 77 (2016).

47. Le Mercier, I. et al. Tumor promotion by intratumoral plasmacytoid dendritic cells is reversed by TLR7 ligand treatment. Cancer Res. 73, 4629-4640 (2013).

48. R Development Core Team. R: A Language and Environment for Statistical Computing (R Foundation for Statistical Computing, Vienna, 2015).

49. Wickham, H. ggplot2: Elegant Graphics for Data Analysis (Springer-Verlag New York, New York, 2009).

50. Dragulescu, A. A. xlsx: Read, write, format Excel 2007 and Excel 97/2000/XP/ 2003 files (The R Foundation, 2014).

51. Wickham, H. Reshaping data with the reshape package. J. Stat. Softw. 21, 1-20 (2007).

52. Li, H. \& Durbin, R. Fast and accurate short read alignment with BurrowsWheeler transform. Bioinformatics 25, 1754-1760 (2009).

\section{Acknowledgements}

The authors want to thank Johannes Textor and Mauro Muraro for supporting the statistical analysis and Michael Valente for enthusiastic discussions. F.W. was supported by a Radboudumc PhD grant. J.T. is supported by NWO-Veni grant 863.130.24 from the Netherlands Organization for Scientific Research and acknowledges generous support by the Eindhoven University of Technology. I.J.M.d.V. received an NWO-Vici award 918.146.55. C.G.F. received the NWO Spinoza award, ERC Advanced Grant PATHFINDER (69019), and Dutch Cancer Society KWO grant 2009-4402. W.T.S.H. acknowledges generous support by the Radboud University and funding from the Ministry of Education, Culture and Science (Gravity program 024.001.035).

\section{Author contributions}

F.W. designed and performed experiments, analyzed results, and wrote the manuscript N.S., N.v.B., D.H. and J.V. performed experiments and analyzed results. I.B.-R., R.W., A.P. and J.F.M.J. performed experiments. A.v.O. and H.D. supervised the research. C.G. F., W.T.S.H. and I.J.M.d.V. supervised the research and wrote the manuscript. J.T. designed and performed experiments, analyzed results, supervised the research, and wrote the manuscript.

\section{Additional information}

Supplementary Information accompanies this paper at https://doi.org/10.1038/s41467018-05784-3.

Competing interests: The authors declare no competing interests.

Reprints and permission information is available online at http://npg.nature.com/ reprintsandpermissions/

Publisher's note: Springer Nature remains neutral with regard to jurisdictional claims in published maps and institutional affiliations.

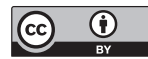

Open Access This article is licensed under a Creative Commons Attribution 4.0 International License, which permits use, sharing, adaptation, distribution and reproduction in any medium or format, as long as you give appropriate credit to the original author(s) and the source, provide a link to the Creative Commons license, and indicate if changes were made. The images or other third party material in this article are included in the article's Creative Commons license, unless indicated otherwise in a credit line to the material. If material is not included in the article's Creative Commons license and your intended use is not permitted by statutory regulation or exceeds the permitted use, you will need to obtain permission directly from the copyright holder. To view a copy of this license, visit http://creativecommons.org/ licenses/by/4.0/.

(C) The Author(s) 2018 